Portland State University

PDXScholar

1979

\title{
A study of the effect of vibration on the residual stresses in a welded fabricated tube
}

Shantini Ratnathicam

Portland State University

Follow this and additional works at: https://pdxscholar.library.pdx.edu/open_access_etds

Part of the Civil and Environmental Engineering Commons Let us know how access to this document benefits you.

\section{Recommended Citation}

Ratnathicam, Shantini, "A study of the effect of vibration on the residual stresses in a welded fabricated tube" (1979). Dissertations and Theses. Paper 2897.

https://doi.org/10.15760/etd.2891

This Thesis is brought to you for free and open access. It has been accepted for inclusion in Dissertations and Theses by an authorized administrator of PDXScholar. Please contact us if we can make this document more accessible: pdxscholar@pdx.edu. 
AN ABSTRACT OF THE THESIS OF Shantini Ratnathicam for the Master of Science in Applied Science presented November 15, 1979 .

Title: A Study of the Effect of Vibration on the Residual Stresses in a Welded Fabricated Tube

APPROVED BY MEMBERS OF THE THESIS COMMITTEE:

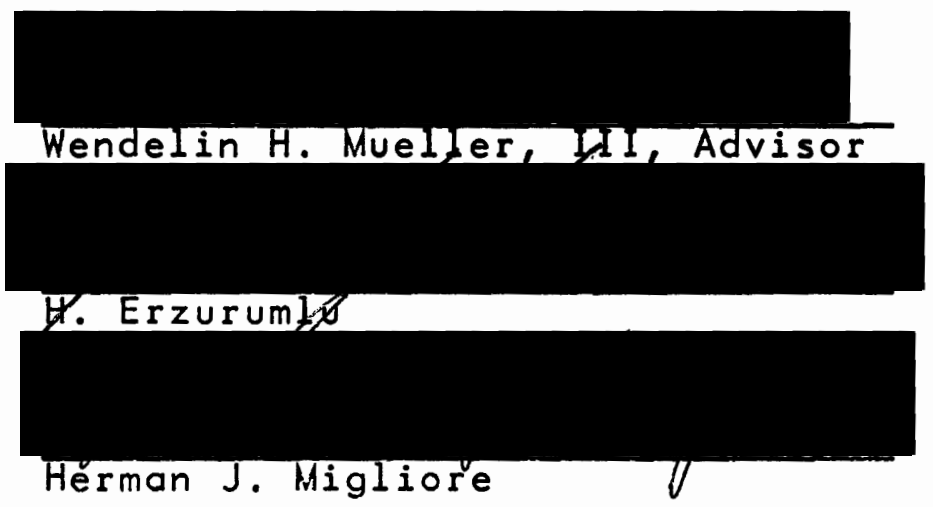

In many instances the predominant factor contributing to structural failure in welded parts is the residual stress which exists before the part is put into service. In this investigation an attempt is made to study the changes in residual stresses caused by vibrational stress relief (VSR). VSR is a fairly new idea in stress relief and there is no substantial evidence of its success in reducing residual stresses. This thesis documents the residual stress distributions found in $5 / 16$ inch thick, 22 inch diameter welded fabricated tubes after VSR.

The method used to determine the residual stresses was the hole drilling technique. In this method a $1 / 8 \mathrm{in}$. diameter hole is drilled in the center of a rosette strain 
gage. The gage measures the disturbed strains as the hole is milled. Using the values of the disturbed strains and calibration coefficients, the residual stresses are calculated. The experimental method used to determine the calibration coefficients eliminates the spot residual stresses caused by drilling. The final residual stress pattern was verified by a transverse and rotational static equilibrium check.

The effect of vibrating ofter welding was studied for. three different positions of the vibrator. In each case a datum residual stress distribution along the circumference of the tube was determined before vibration. A second set of gages was mounted on the stationery tube and the residual stress pattern after vibration was obtained.

The effect of vibrating during welding was also studied. In this case the stresses in the tube were compared to those of a similar tube welded under normal conditions.

The procedure involved in VSR was to clamp a vibrator onto the tube, and vibrate the system just below resonance for approximately 20 minutes.

The effects of the above vibrational procedures on the residual stress patterns are reported. Principal residual stress measurements were made ot several points around the circumference of the tube. The longitudinal component of the stress revealed changes in certain cases but no significant stress relief is claimed. 


\title{
A STUDY OF THE EFFECT OF VIBRATION
}

ON THE RESIDUAL STRESSES IN A WELDED FABRICATED TUBE

by

Shantini Ratnathicam

A thesis submitted in partial fulfillment of the requirements for the degree of

\author{
MASTER OF SCIENCE \\ IN \\ APPLIED SCIENCE
}

Portland State University

1979 
TO THE OFFICE OF GRADUATE STUDIES AND RESEARCH:

The members of the Committee approve the thesis of

Shantini Ratnathicam presented November 15, 1979.

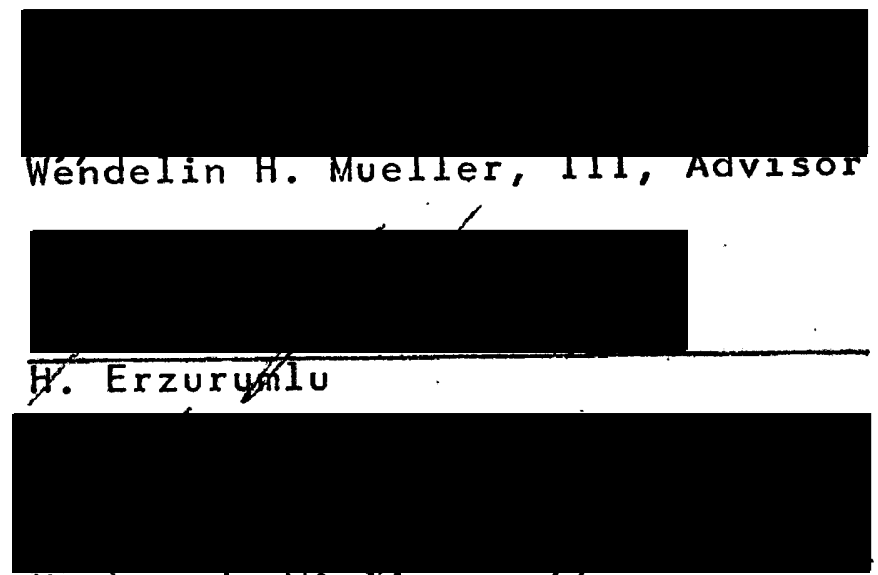

Herman J. Migfiore

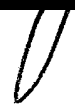

APPROVED:

FFanz $N$. Rad, Head, Civil-structural Engineering

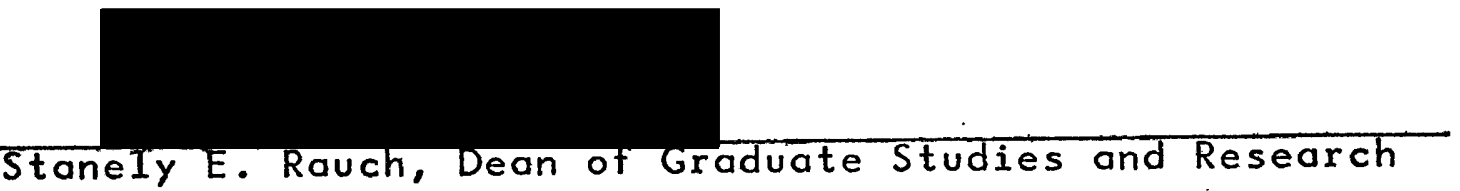


TO

MY FAMILY 


\section{ACKNOWLEDGMENTS}

The author gratefully acknowledges the help received from several sources. She is indebted to DR. WENDELIN $H$. MUELLER, for his advice, guidance and encouragement throughout the course of this study, and in preparing this document. Also deeply appreciated is the help extended, and the valuable suggestions made by DR. HERMAN MIGLIORE, at all stages of this investigation. The author wishes to thank the other members of the thesis committee: DR. H. ERZURUMLU and DR. LAIRD BRODIE, for their helpful comments.

Appreciation and thanks are extended to Steve Speer and Sophia Fagen for their help in the experimental work, to Robert Sipe for the graphics, and to Donna Mikulic for the typing.

The author also thanks the members of the Oregon Graduate Center for their technical assistance and the use of their equipment.

Finally the author thanks her husband Jayanthan for his interest and encouragement in all her graduate work. 


\section{TABLE OF CONTENTS}

PAGE

ACKNOWLEDGMENTS

i v

LIST OF TABLES

vi i

LIST OF FIGURES

viii

LIST OF SYMBOLS

$x$

CHAPTER

I INTRODUCTION

1.1 Review of Literature

1

1.2 Objective of this Investigation

4

6

II VIBRATION AFTER WELDING

2.1 Material Data

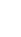

2.2 Vibration in Principal Directions After Welding

2.3 Vibration in Skew Direction After Welding

II VIBRATION DURING WELDING

3.1 Material Data

3.2 Experimental Set Up 26

3.3 Results 26

IV EQUILIBRIUM CHECK AND ACCURACY OF RESULTS 30

4.1 Equilibrium Test 32

4.2 The Effect on Moment Balance
Due to Axis Shift

4.3 Check for Symmetry 34 
4.4 Stress Changes due to Variation in Calibration Coefficients

4.5 An Estimate of the Error Caused in Measuring High Residual Stresses by Hole Drilling

$V$. CONCLUSIONS AND RECOMMENDATIONS

5.1 Summary of Results

5.2 Conclusions

5.3 Recommendations

APPENDIX A Summary of hole drilling method for determination of residual stresses

APPENDIX B Computation of stresses using the data obtained from the hole drilling method

APPENDIX C The strain separation method for experimental determination of calibration coefficients

APPENDIX D Computer program for summation of forces and moments 


\section{LIST OF TABLES}

TABLE

PAGE

I Data from hole drilling method, for

vibration in the principal

directions after welding

I Residual stresses present after

vibration in the principal directions,

of ter welding

II Hole drilling data and resulting residual

stresses after vibration in skew direction

IV Residual stresses after VSR

during welding

$\checkmark$ Result of equilibrium test

VI Result of equilibrium test after axis shift

VII Results of symmetry check

VIII Determination of calibration coefficients by the strain separation method

IX Data from calibration experiments by the strain separation method

$X$ Calibration coefficients obtained for different trials

$X I$ Variation of stresses with different calibration coefficients

XII Variation of the longitudinal stress as a fraction of the yield stress

XIII Experimental data for estimation of error caused in measuring high residual stresses by hole drilling

XIV Estimate of error caused in determining high residual stresses by hole drilling

XV Calculation of corrected strain 


\section{LIST OF FIGURES}

FIGURE

PAGE

2.1 Experimental set up for vibration with the axis of the vibrator perpendicular to the longitudinal axis of the tube

2.2 Experimental set up for vibration with the axis of the vibrator parallel to the longitudinal axis of the tube

2.3 Longitudinal residual stresses before and after VSR in principal directions

2.4 Experimental set up for vibration in skew direction

2.5 Longitudinal residual stress distribution before and after vibration in skew direction

3.1 Set up for vibration during welding 24

3.2 Ready for inside weld pass 24 3.3 Heat affected zone after inside pass
and before outside pass

3.4 Heat affected zone and outside weld 25

3.5 Longitudinal residual stress distribution before and after VSR during welding

4.1 Longitudinal stress distribution on the second half of the tubes' cross section

4.2 Range of variation in the longitudinal residual stress distribution due to different calibration coefficients

B.l Radial and tangential strains at a point

B.2 Position of gages with respect to principal stresses and weld

B.3 Location of $\sigma_{L}$ when $\sigma_{1}$ is known 60

B.4 Mohr's circle 60 
PAGE

C.l Example of graphical interpolation used in strain separation

C.2 Orientation of gages on test plate 69

D.l General element of curve 75

D.2 Cross section of tube 76

$\begin{array}{lll}\text { D. } 3 \text { Flow chart } & 77 .\end{array}$ 


\section{LIST OF SYMBOLS}

A - Calibration coefficients

B - Calibration coefficients

D - Difference in strains $\left(\varepsilon_{a}-\varepsilon_{c}\right)$

E - Nodulus of elasticity

G - Shear Modulus

$M \quad$ - Bending moment

My - Moment at which yield point is reached in flexure

P - axial load

$P_{y}$ - axial load corresponding to yield stress level

$R$ - Distance of gage to hole center

$R_{0} \quad$ - radius of drilled hole

$r \quad$ - Ratio of $R$ to $R_{0} ; R / R_{0}$

$S$ - sum of strains $\left(\varepsilon_{a}+\varepsilon_{c}\right)$

a - angle from principal stress direction to radial direction

$\beta \quad$ - angle from direction of principal stress $\sigma_{1}$ to gage a

$\varepsilon_{\text {a }} \quad$ - strain measured by gage a

$\varepsilon_{b} \quad$ - strain measured by gage b

$\varepsilon_{c} \quad$ - strain measured by gage c

$\varepsilon_{r} \quad$ - strain in radial direction

$\varepsilon \quad$ - strain in tangential direction

$\mu$ - Poisson's ratio

$\sigma_{1}$ - principal stress

$\sigma_{2}$ - principal stress 
$\sigma_{L}$ - longitudinal sesidual stress i.e., in direction of weld in the tube

${ }^{\sigma} T$ - transverse or circumferential residual stress

$\sigma_{y}$ - yield stress

cps - cycles per second, Hertz 


\section{CHAPTER I}

\section{INTRODUCTION}

\subsection{REVIEW OF LITERATURE}

Tubular members are commonly used in off shore structures, because of their ability to resist bending equally well in any direction. They also exhibit greater flexural reserve strength beyond first yield than the wide flanged shapes, and are not subjected to lateral-torsional buckling. The response of tubular members to combined bending and axial loads has to be established for economical design. Tubular members are fabricated by cold rolling steel plate into a cylindrical shape and then welding along the longitudinal seam. This weld causes residual stresses in the tube due to the restriction of the shrinkage during cooling. The magnitude and distribution of the residual stresses in a welded fabricated tube has been established (1). These stresses are fairly high and tend to reduce the strength in stability, fatigue and fracture of a member $(2,3)$.

Reliable stress relief methods would lead to better utilization of the material resulting in smaller and lighter members to carry the same loads. Historically, thermal stress relief has been used to relieve residual stresses caused by welding. In thermal methods the object is heated 
in a furnace until the yield strength of the material has been lowered to the point of rapid creep. Heat treatment of large members is limited by the size of the furnace. It is costly due to the large amount of energy needed for the heating and the time lost due to the lengthy process. often the components are heavy and transport to the furnace is troublesome. Sometimes property changes in the material at the high temperature are undesirable.

An alternate relatively new stress relief method is mechanical vibration. Vibratory stress relief gained a footing in Europe following World War II. Germans began investigating the possibility of vibratory stress relief as an alternative to the costly rebuilding of their heat treatment facilities. In 1969 a survey (4) found major fabricators in the United States using or evaluating Vibratory Stress Relief

There is evidence $(4,5)$ that VSR is effective in minimizing the distortion in machined components and achieving high tolerances. Voest-Alpine Co., of Austria is using VSR on machine housings, gray iron castings and shafts before they are finish machined. The resulting dimensional stability is reported as "almost identical" compared to annealing. Somat Corp., Pomeroy, Pa., has used VSR for eight years to maintain required close tolerances and eliminate tool breakage in their weldments for waste disposal systems. Herman Corp., Zelienople, Pa., uses VSR on weldments, composed of castings, hot and cold rolled 
steels weighing 15,000-28,000 lbs, apiece. "Occasional" use of VSR during welding to decrease distortion is also reported (5). Karmann, a German automobile firm uses VSR to achieve tolerances in the range of hundredths of a millimeter. Commercial vibratory stress relief (VSR) equipment is now available. Though claims are being made that stress relief could be achieved by vibration during or after welding, there is no published evidence that residual stress levels are significantly reduced due to vibrational treatment.

Vibratory treatment has the advantage of being simple. It consists of clamping a portable vibrator onto the workpiece and vibrating at a frequency around resonance for about 20-30 minutes. The vibrator commercially available is a variable speed motor driving an eccentric mass to give vibrational frequencies up to $100 \mathrm{~Hz}$.

The present knowledge of the actual vibrational conditioning is summarized as follows: (4)

"Mechanical mechanisms propose that vibrational stress added to residual stress causes plastic flow and consequent stress relief. Metallurgical mechanisms usually involve dislocations and pinning."

A dislocation is a line defect or a row of missing atoms, in a crystal lattice leading to a region of easy slip. However as more slip occurs dislocations interact, pile 
up and form dislocation tangles resulting in pinning. In cold worked metals dislocation tangles make further slip and plastic flow more difficult and hence the effect of vibrational conditioning could be limited.

Many methods of measuring residual stresses have been used in the past and the merits of each evaluated (1). The hole drilling technique of measuring residual stresses is used in this investigation, due to its reliability and simplicity. It consists of drilling a hole in a test piece by means of a rotating cutter and measuring strains disturbed using a strain gage. The strains are converted to stresses using calibration coefficients which reflect properties of the test material and the hole diameter. The strain separation method of determining calibration coefficients is used as it was shown (1) to be the most accurate.

It consists of applying known stresses to a sample of the test material and measuring the strains. The strain component caused only by the applied stress can be computed by this method.

\subsection{OBJECTIVE OF THIS INVESTIGATION}

The purpose of this investigation is to determine the longitudinal residual stresses present in a welded fabricated tube after VSR. The residual stress distribution before vibration has already been investigated by the same method, and the results are available for comparison (1). 
The present investigation is in two stages.

1. The same tube used by Tran (1) was vibrated and residual stress measurements were made by the hole drilling method. Three positions of the vibrator were investigated.

2. A similar new tube was fabricated and was vibrated during welding. The residual stresses present in it were similarly measured. 


\section{CHAPTER II}

\section{VIBRATION AFTER WELDING}

Vibratory stress relief (VSR) treatment could be applied to welded components in two different ways. The component could be vibrated either while it is being welded or after the weld has cooled. The VSR treatment applied to a tube ofter welding, and the resulting residual stresses are documented in this chapter.

The effect of the vibration may depend on the direction of the vibratory motion. Post weld vibratory treatment was performed on the same tube with different vibrator positions. Residual stress measurements were made after vibrational treatment in each direction. Therefore stress measurements made at each stoge of the study, reflects a combined effect of all previous vibrations on the tube. The residual stress distribution in this same tube before any VSR treatment has been determined experimentally and is documented in (1).

\subsection{MATERIAL DATA}

A) Tube and strain gages.

The steel tube specimen had the following characteristics. 
Length: $6 \mathrm{ft}$

Outside diameter: 22 inches

Wall thickness: $5 / 16$ inch

The tube was fabricated from an American made mild steel plate with the following properties.

Specification: ASTM A36.75

Yield stress: $40.9 \mathrm{ksi}$

Ultimate stress: $61.5 \mathrm{ksi}$

Percent elongation: $28.5 \%$

Chemical analysis:

$$
\begin{array}{ll}
\text { Carbon: } & .14 \% \\
\text { Manganese : } & .67 \% \\
\text { Phosphorus : } & .009 \% \\
\text { Sulfur: } & .018 \% \\
\text { Silicon: } & .22 \%
\end{array}
$$

The strain gages used were $45^{\circ}$ rectangular rosettes. They are manufactured by Micro-measurements $M-M$, Romulas, Michigan, primarily for residual stress determination by the hole drilling method.

Gage type 1: EA-06-125RE-120

$$
\text { gage factor at } 75^{\circ} \mathrm{F} ; 2.01 \pm .05
$$

Gage type 2: EA-13-125RE-120

$$
\text { gage factor at } 75^{\circ} \mathrm{F} ; 2.08 \pm 1.5
$$

These rosettes were used with a drill bit of .125 inch diameter. The surface cleaners and bonding agents used were also manufactured by Micro-measurements. 
B) Vibrating equipment.

A META-LAX 1020 mechanical stress relief machine manufactured by Bonal Corporation, Detroit, Michigan, was used for all the vibrational conditioning in this study. The equipment consists of the following components. 1) Vibration inducer: (vibrator) It is a variable speed motor driving an eccentric mass.

Model number: 20

Serial number: 882

Voltage: 115 volts D.C.

Max. Current: 3 amps D.C.

D.C. power: $1 / 3 \mathrm{hp}$

2) Console: This is the control switchboard unit, and is connected to the vibrator and transducer. The control components are the frequency adjustment knob, digital frequency readout, peakmeter, timer, timer switch, and the power switch.

3) Transducer with clamp: The transducer senses vibration and translates it into an electrical signal proportional to the amplitude of the vibration. It is clamped onto the workpiece oway from the vibrator.

4) Rubber isolation pods.

C) Hole drilling equipment.

The RS-200 milling guide kit manufactured by Photolastic Inc., Malvern, Pennsylvania, was used for the experimental determination of the residual stresses. The 
milling guide allows precise alignment to within \pm .001 inch of the gage center, and insures the concentricity and guidance of the miliing bar, to which the drill bit is attached. A portable $3 / 8$ inch variable speed drill with a $1 / 8$ inch bit was used.

D) Strain indicator.

Vishay/DATRAN II: Strain measurement and recording system manufactured by Vishay Instruments, Inc.

Strain indicator: Model 321

Scanner: Model 330

This system has an accuracy of $\pm .1 \%$ of reading $\pm_{2 \mu \varepsilon}$, in a measurement range of $10,000 \mu \varepsilon$.

\subsection{VIBRATION IN PRINCIPAL DIRECTIONS AFTER WELDING}

The longitudinal axis of the vibrator was positioned along two principal directions, with reference to the longitudinal axis of the weld. One parallel and the other perpendicular.

2.2.I Experimental set up for vibration.

1) Axis of vibrator perpendicular to weld.

The vibrator was mounted onto the horizontal surface of a piece of wood shaped to the curvature of the tube and clamped to the edge of the tube as shown, in Fig. 2.1. The tube rested on isolation pads placed on the floor. Rigid body movement of the tube was prevented by a wooden framework which was fastened to the floor slab. 
10

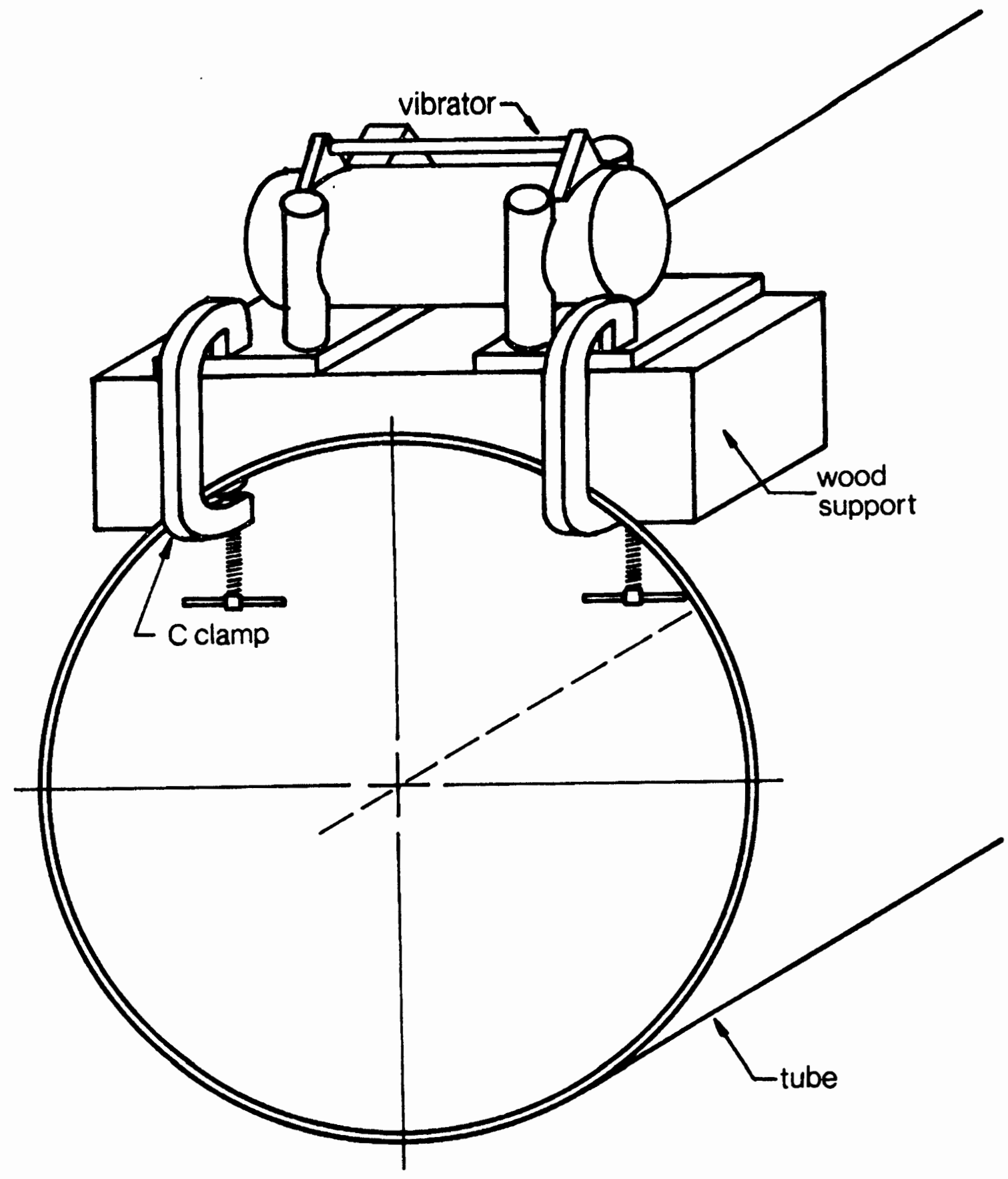

Figure 2.1.

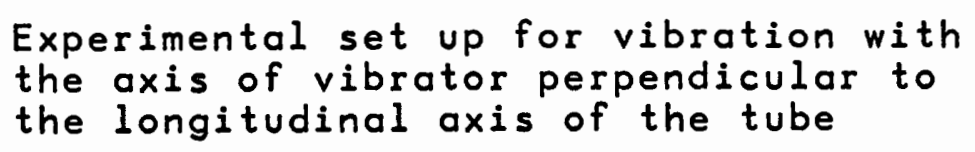


The transducer was clamped to the opposite edge of the tube. The frequency of resonance of the tube was 34 cps. The frequency was adjusted to $28 \mathrm{cps}$, and the vibration time set to 20 minutes. The tube was vibrated at this frequency below resonance as recommended by META-LAX.

2) Axis of vibrator parallel to weld. The vibrator position was changed by rotating it through 900 , and the rest of the set up was identical to that described above. One end of the vibrator was clamped directly to the edge of the tube using two " $C$ " clamps (fig. 2.2). The other end of the vibrator was left unclamped as it proved to be stable during vibration. The tube was vibrated at a frequency of 22 cps for 20 minutes. The resonance frequency for this set up was 27 cps.

2.2.2. Tabulation of results.

Residual stress measurements were made by the hole drilling method outlined in Appendix $A$. The data correspond to the following cases considered.

Case 1: Before VSR to check on data from (1).

Case 2: After VSR with vibrator axis perpendicular to the weld.

Case 3: After VSR with vibrator axis parallel to the weld.

Case 4: Before VSR (1). The curve has been modified slightly from its original form to accommo- 


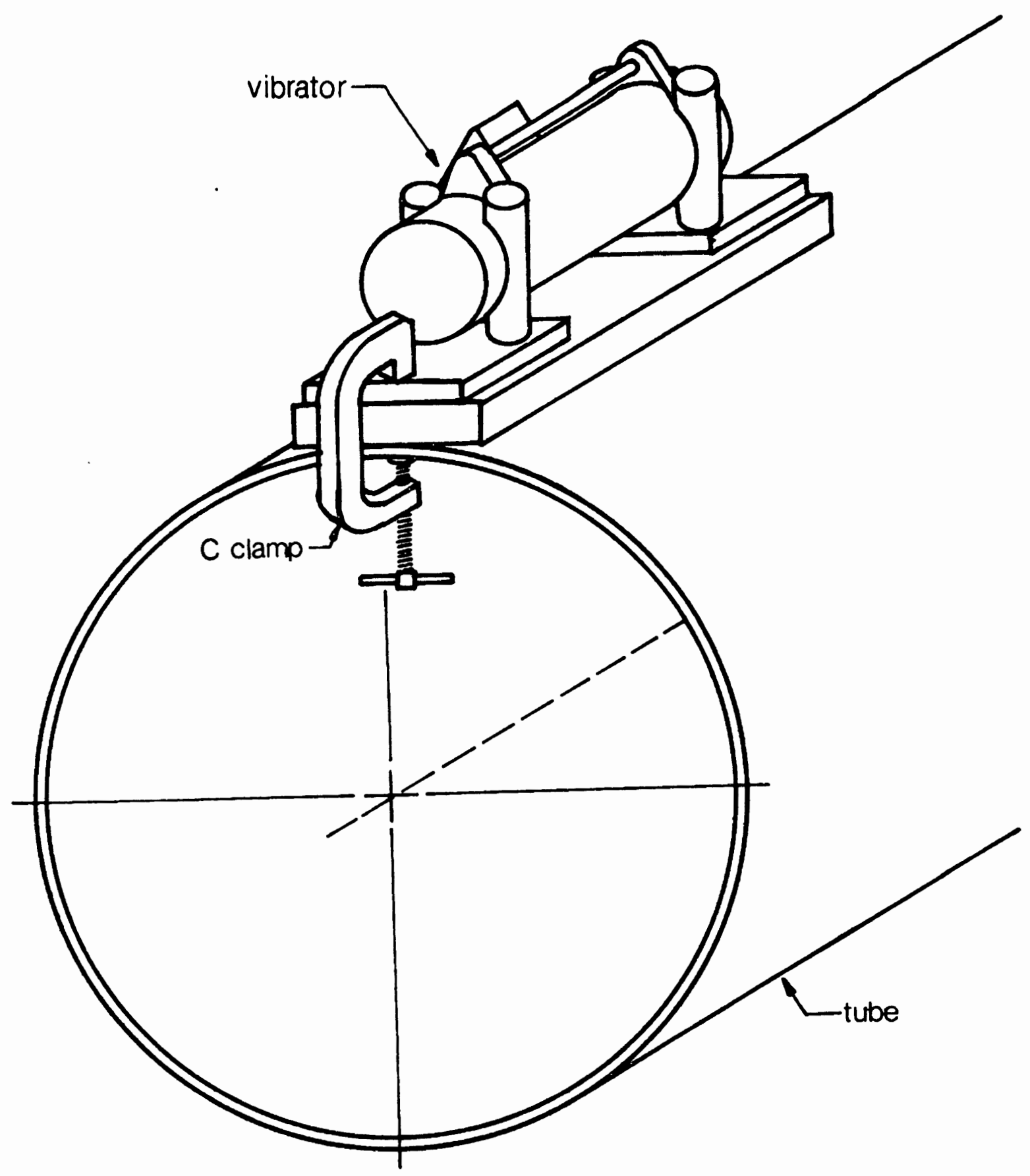

Figure 2.2. Experimental set up for vibration with the axis of vibrator parallel to the longitudinal axis of the tube 
date the data point "near weld", using the exact value of $\theta=.08$, instead of the approximate value of $\theta=0$.

The raw data for cases 1,2 and 3 is given in Table I. The holes for each of the three cases were drilled at three different cross sections spaced 2 inches apart. A minimum distance of 1.5 inches between holes is maintained for all holes drilled, throughout this investigation. The strains tabulated correspond to the total disturbed strain at a hole depth of .135 inches. The angle $\theta$, is the angle subtended at the center of the circular cross section by the center of the hole and the centerline of the weld (Fig. D.2, Appendix D).

The resulting residual stresses present after each case, is given in Table II. They were calculated using the data in Table I, and as detailed in Appendix B. The calibration coefficients used to calculate the stresses are from Tran (1), obtained by the strain separation method (Appendix C). This pair of coefficients is the most accurate (1). Using the same coefficients is justified by the fact that the type of gages and tube used was identical. The value of $\sigma_{y}$ is the yield strength of the steel plate as reported in the mill sheet. It is the yield strength of the plate before cold rolling to the cylindrical shape. 
TABLE I

DATA FROM HOLE DRILLING METHOD FOR VIBRATION IN THE PRINCIPAL DIRECTIONS AFTER WELDING

\begin{tabular}{|c|c|c|c|c|c|}
\hline \multirow{2}{*}{$\begin{array}{c}\text { HOLE } \\
\#\end{array}$} & \multirow{2}{*}{$\begin{array}{c}\theta \\
\text { (RADIANS) }\end{array}$} & \multicolumn{3}{|c|}{$\begin{array}{c}\text { MEASURED STRAINS } \\
\text { (MICRO-STRAINS) in } / \text { in }\end{array}$} & \multirow{2}{*}{ CASE } \\
\cline { 3 - 5 } & $\varepsilon_{a}$ & $\varepsilon b$ & $\varepsilon_{c}$ & \\
\hline 1 & .196 & +114 & +116 & +084 & 1 \\
4 & .589 & +129 & +077 & +070 & 1 \\
7 & 1.572 & -044 & -052 & -070 & 1 \\
2 & .196 & +123 & +132 & +061 & 2 \\
5 & .589 & +058 & +035 & +084 & 2 \\
3 & .196 & -014 & +172 & +099 & 3 \\
CC & .589 & +062 & +004 & +057 & 3 \\
8 & 1.572 & -069 & -079 & -067 & 3 \\
AC & .090 & -054 & +271 & -051 & 3 \\
AS & .090 & -054 & +300 & -034 & 3 \\
\hline
\end{tabular}


TABLE II

RESIDUAL STRESSES PRESENT AFTER VIBRATION

IN THE PRINCIPAL DIRECTIONS AFTER WELDING

\begin{tabular}{|c|c|c|c|c|c|}
\hline \multirow{2}{*}{$\stackrel{\theta}{(R A D I A N S)}$} & \multirow{2}{*}{$\begin{array}{l}\text { STRESSES* } \\
(\text { KSI })\end{array}$} & \multicolumn{4}{|c|}{ CASE NUMBER } \\
\hline & & 1 & 2 & 3 & 4 \\
\hline \multirow[t]{3}{*}{.196} & $\sigma_{L}$ & -16.7 & -17.7 & -18.1 & -13.1 \\
\hline & $\sigma_{T}$ & -13.7 & -10.6 & +5.1 & -6.3 \\
\hline & $\sigma_{L} / \sigma_{y}$ & -.41 & -.43 & -.44 & -.32 \\
\hline \multirow[t]{3}{*}{.589} & $\sigma_{L}$ & -17.3 & -14.2 & -14.1 & -12.6 \\
\hline & $\sigma_{T}$ & -13.3 & -7.7 & -4.2 & -4.7 \\
\hline & $\sigma_{L} / \sigma_{y}$ & -.42 & -.35 & -.34 & -.31 \\
\hline \multirow[t]{3}{*}{1.57} & $\sigma_{L}$ & +8.3 & & +9.5 & +6.0 \\
\hline & $\sigma_{T}$ & +9.2 & & +11.4 & +12.1 \\
\hline & $\sigma_{L} / \sigma_{y}$ & .20 & & +.23 & +.15 \\
\hline \multirow[t]{6}{*}{.090} & $\sigma_{L}$ & & & +37.1 & +30.6 \\
\hline & $\sigma_{T}$ & & & -20.9 & -8.9 \\
\hline & $\sigma_{L} / \sigma_{y}$ & & & +.90 & +.75 \\
\hline & $\sigma_{L} L$ & & & +30.6 & \\
\hline & $\sigma_{T}$ & & & -24.0 & \\
\hline & $\sigma_{L} / \sigma_{y}$ & & & +.92 & \\
\hline
\end{tabular}

* $4 A=-1.30 \times 10^{-8}$

$4 B=-2.23 \times 10^{-8}$

$\sigma_{y}=40.9 \mathrm{KSI}$ 


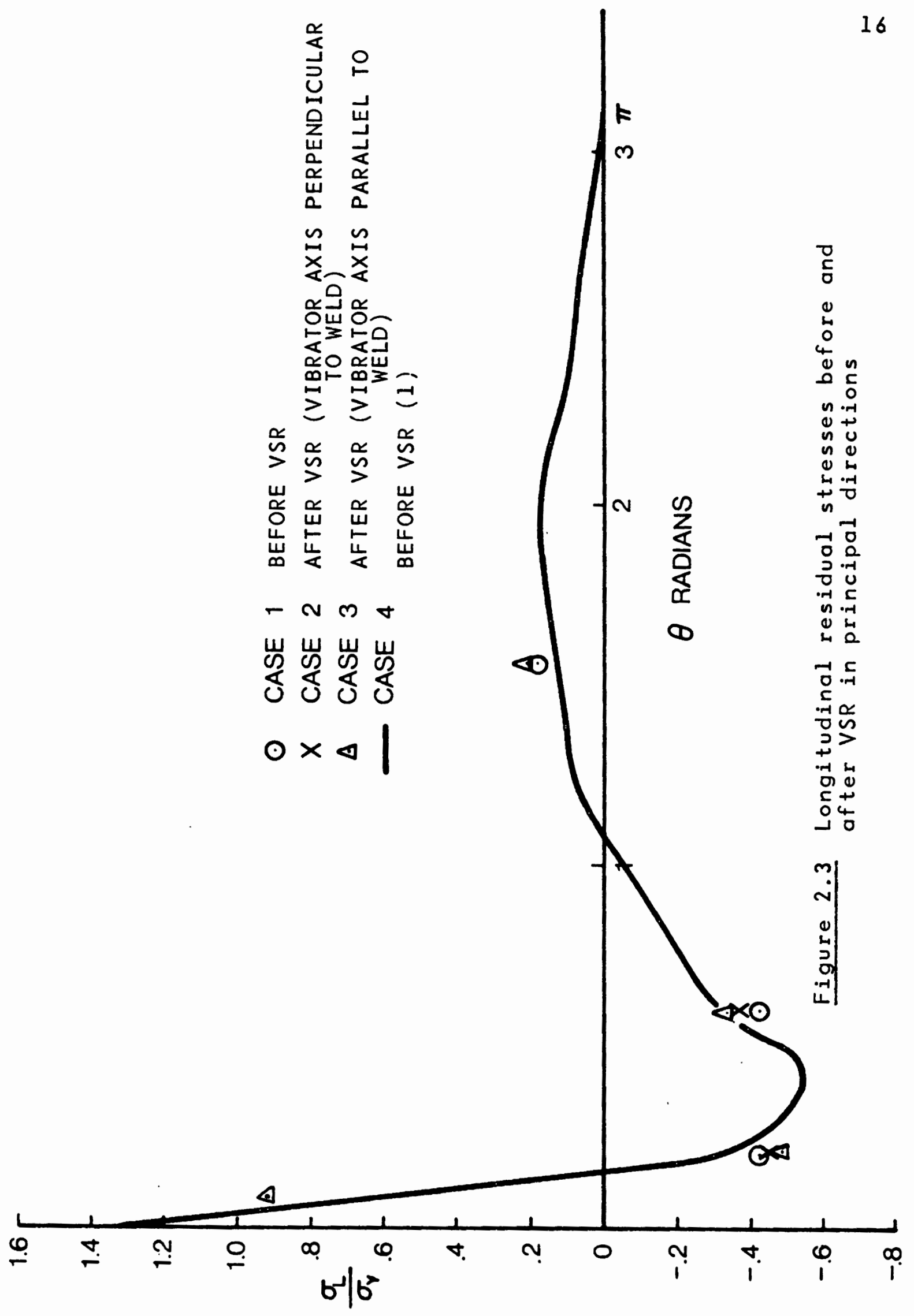


2.2.3 Graphical presentation of result. (Fig. 2.3)

The results in Table II are presented graphically by a plot of the longitudinal stress distribution along one half of the cross section originating from the weld. The data points corresponding to the measured stresses for each case are shown, and compared to Case 4.

\subsection{VIBRATION IN THE SKEW DIRECTION AFTER WELDING}

The same tube was next vibrated with the vibratar axis at an angle of 300 to the axis of the weld. 2.3.1 Experimental set up. (Fig. 2.4)

The vibrator and tube were both independently clamped onto a "vibration table". This table consisted of - large rigid metal plate $\left(6^{\prime} \times 4^{\prime} \times 1^{\prime \prime}\right)$, supported ot its four corners on spherical rubber spring pads, giving it degrees of freedom in three dimension. The tube was placed diogonally on the table top and clamped at its two edges as shown. The vibrator was placed on the table and clamped along one side of it. The approximate angle on the horizontal plane between the longitudinal axis of the weld and the vibrator axis was $30^{\circ}$. The tube was vibrated for 20 minutes at its resonance frequency of $47 \mathrm{cps}, \pm 1$ cps, for four weld locations. The tube was rotated relative to the vibration table, with the weld seam touching the table, $180^{\circ}$ from the table, and two positions in between. Therefore, the total treatment was 80 minutes. 


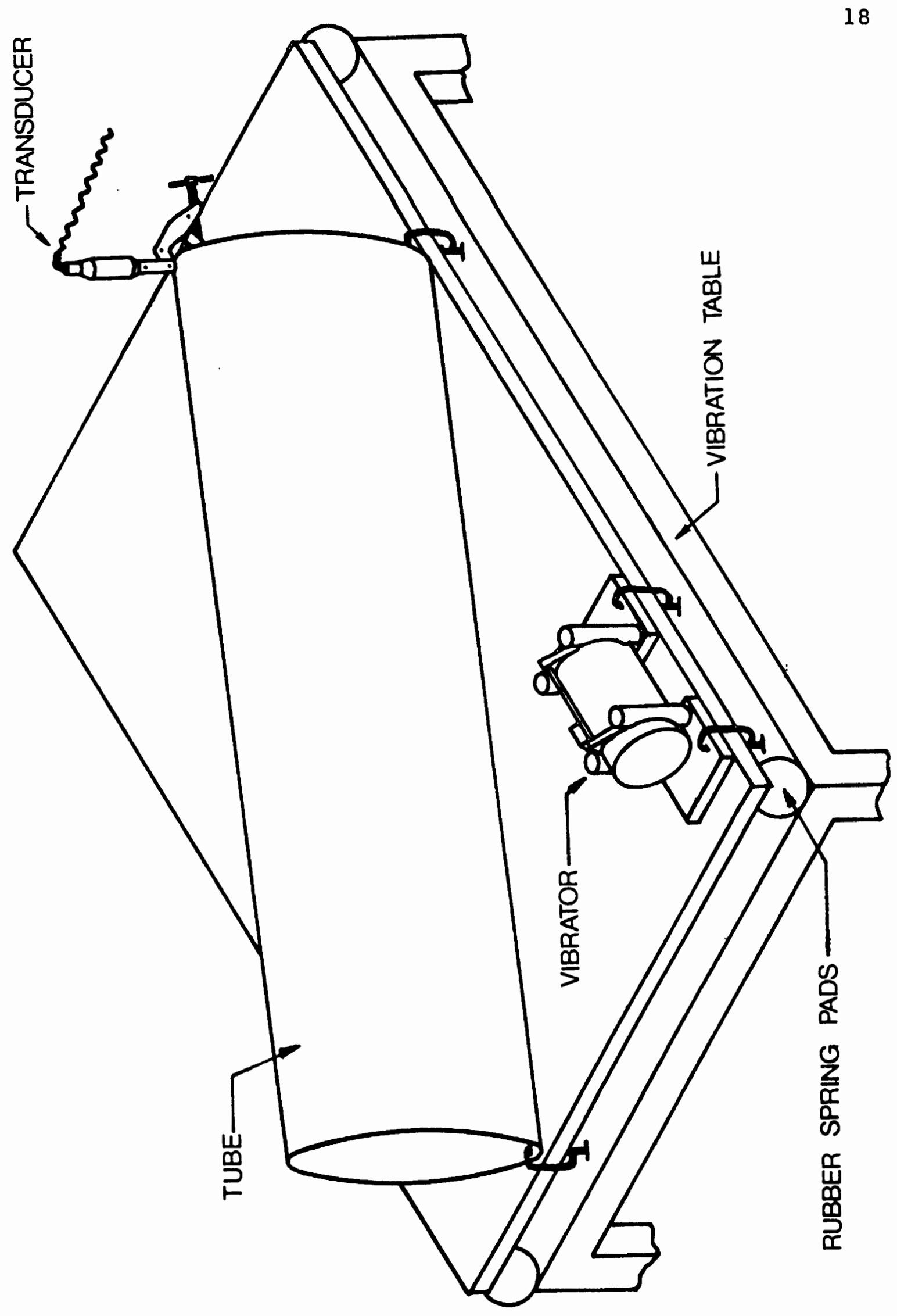

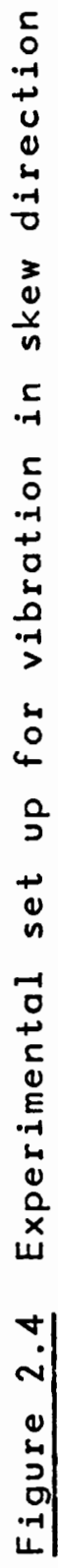


2.3.2 Tabulation of results

Due to a short supply nationally of the usual gage type EA-06-125RE-120, gage type EA-13-125RE-120 was used to determine the residual stresses after VSR in the skew direction. The difference in the two gage types is the coefficient of thermal expansion of the gage material. The calibration coefficients for these gages were found by the strain separation method (Appendix C). The measured strains, calibration coefficients used and the resulting stresses are given in Table III.

2.3.3 Graphical presentation of results. (Fig. 2.5)

The longitudinal residual stress distribution in the tube after the skew vibration is plotted here using data in Table III. This stress distribution is at a circular cross section at a distance of 38 inches from the edge of the tube. It is compared to the stresses measured prior to VSR in the skew direction (i.e., Case 3 in Fig. 2.3). 
TABLE III

HOLE DRILLING DATA AND RESULTING RESIDUAL STRESSES AFTER VIBRATION IN THE SKEW DIRECTION

\begin{tabular}{|c|c|c|c|c|c|c|}
\hline \multirow[t]{2}{*}{$\begin{array}{c}\theta \\
(\text { RADIANS })\end{array}$} & \multicolumn{3}{|c|}{$\begin{array}{l}\text { MEASURED STRAINS } \\
\text { (MICRO STRAINS) }\end{array}$} & \multicolumn{2}{|c|}{$\begin{array}{l}\text { CALCULATED STRESSES* } \\
\text { (KSI) }\end{array}$} & \multirow{2}{*}{$\frac{\sigma L}{\sigma y}$} \\
\hline & $\varepsilon_{a}$ & $\varepsilon_{b}$ & $\varepsilon_{c}$ & $\sigma L$ & $\sigma_{T}$ & \\
\hline .08 & -065 & +257 & -072 & +39.6 & -16.0 & .97 \\
\hline .34 & +106 & +110 & +070 & -13.3 & -17.0 & -.32 \\
\hline .61 & +102 & +005 & +010 & -14.0 & -5.3 & -.34 \\
\hline .87 & -018 & -052 & -032 & +2.0 & +6.6 & +.05 \\
\hline 1.16 & -068 & -104 & -056 & +7.1 & +14.3 & +.17 \\
\hline 1.43 & -064 & -096 & -112 & +14.5 & +15.9 & +.35 \\
\hline
\end{tabular}

$\begin{aligned} * 4 A & =-1.16 \times 10^{-8} \\ 4 B & =-2.34 \times 10^{-8}\end{aligned}$ 


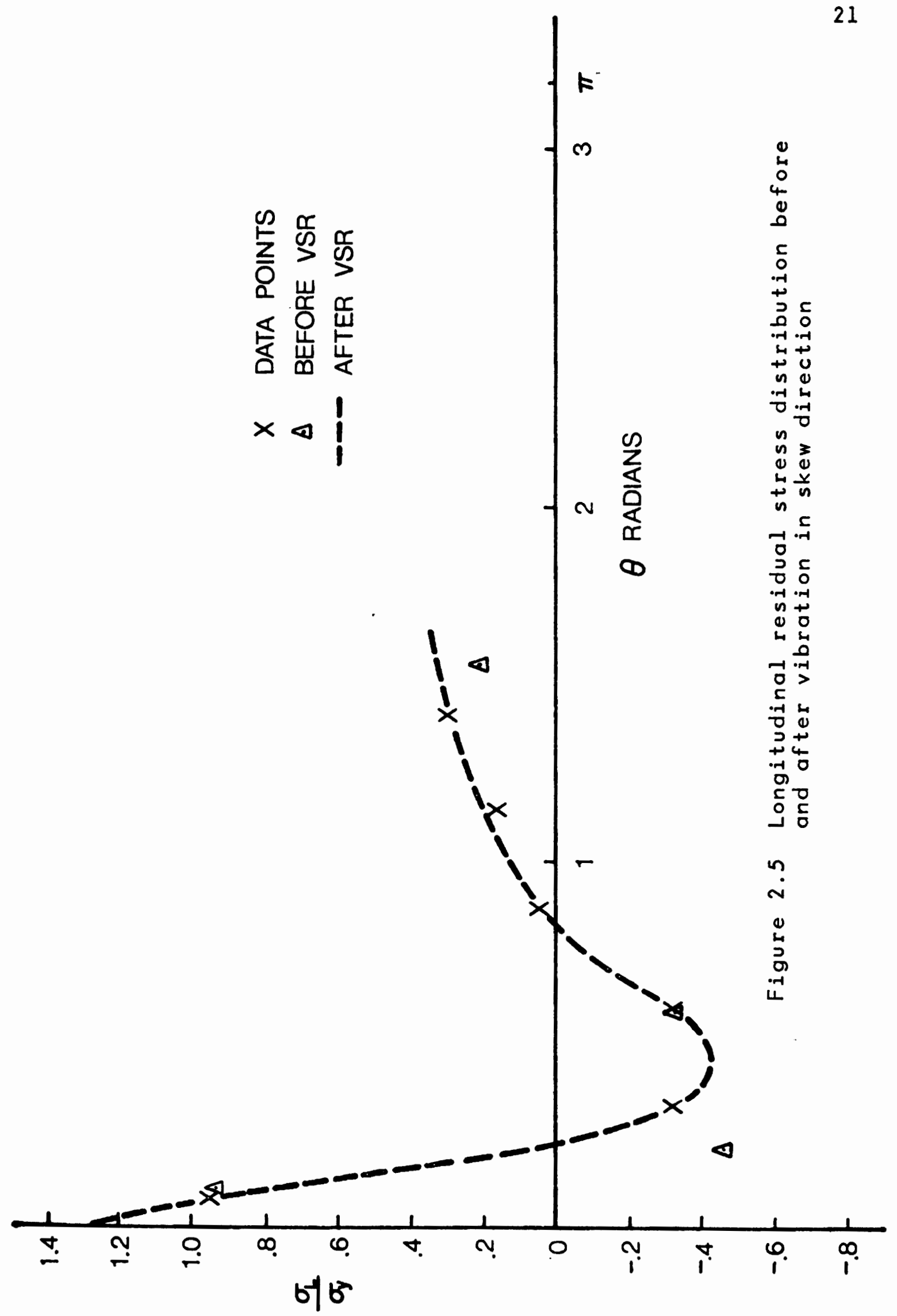




\section{CHAPTER II I}

\section{VIBRATION DURING WELDING}

A second tube similar to the one detailed in chapter two was used for this phase of the investigation. The only difference in the fabrication process was that the tube was vibrated while it was being welded. The VSR treatment applied during the welding and the resulting residual stresses in the tube, are presented in this Chapter.

\subsection{MATERIAL DATA}

A) Tube

The steel tube specimen had the following characteristics:

Length: 6 feet

Outside diameter: 22 inches Wall thickness: $5 / 16$ inch

The tube was fabricated from a mild steel plate made by Nippon Steel Corporation with the following properties:

Specification: ASTM A 36.74

Yield stress: $48.2 \mathrm{KSI}$

Tensile Stress: $66.1 \mathrm{KSI}$

Percent elongation: $28 \%$

Chemical analysis

Carbon: .21\% 
Manganese: $.69 \%$

Phosphorus: $.16 \%$

Sulfur: $\quad .16 \%$

Silicon: $.06 \%$

B) Weld

The welding conditions were as follows:

Weld type: Butt, $60^{\circ}$ included angle bevel

Weld process: GMAW, gas metal arc welding

Weld current: $250-260$ amps

Arc voltage: 30 volts

Rate of welding: approx. 12 inch per minute

Filler wire: Spoolarc 85, 045 inch

Shielding gas: Argon

The spoolarc 85 filler material had the following characteristics:

Specification: ANS A5 $\cdot 18-69$

Type: E $70 \mathrm{~S}-3$

Wire diameter: .045 inch

Yield stress: $67.6 \mathrm{KSI}$

Tensile stress: $82.2 \mathrm{KSI}$

Percent elongation: $26.5 \%$

Charpy V-notch impacts @ $0^{\circ} \mathrm{F}: 35 \mathrm{ft}-1 \mathrm{~b}$

The vibration and stress determination equipment are the same as those detailed in chapter two. 


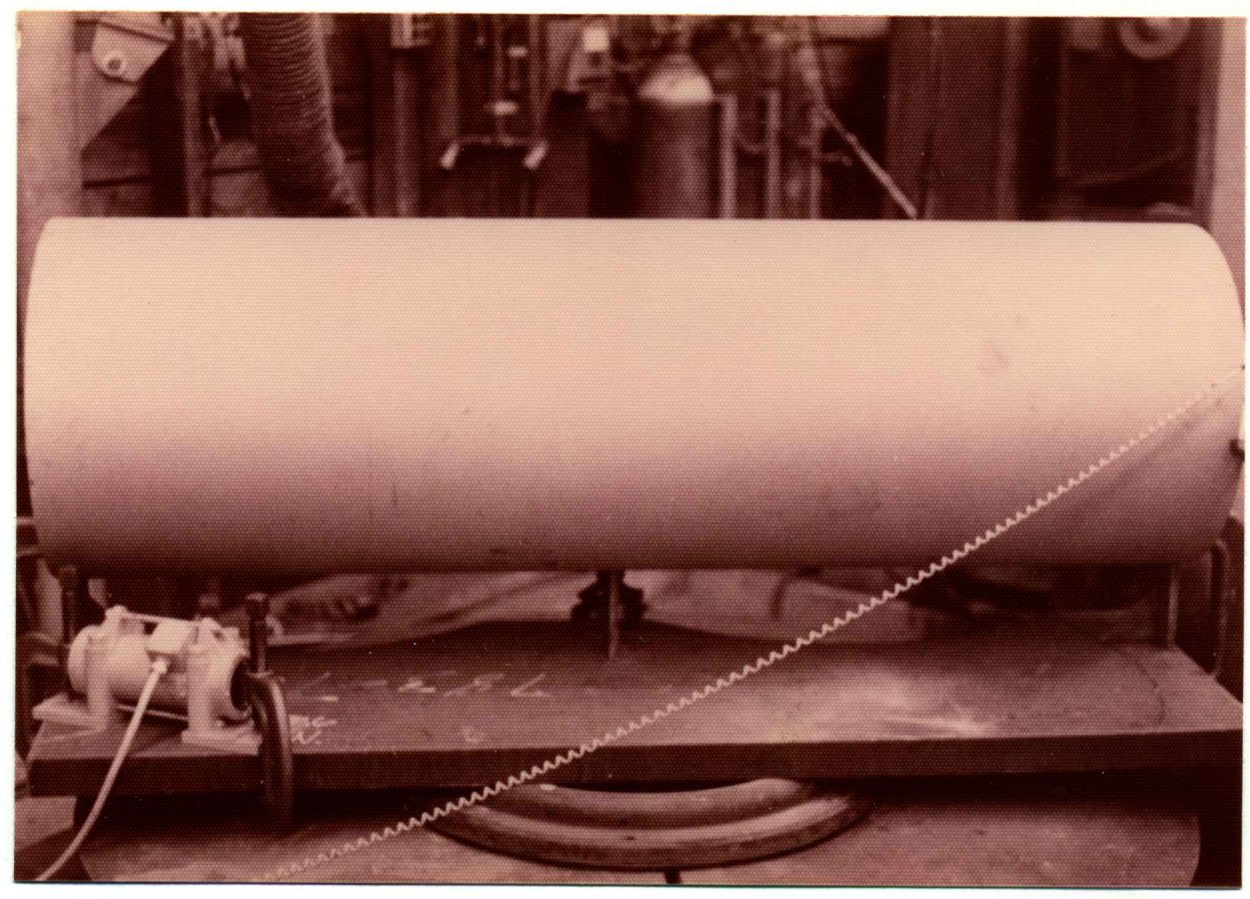

Figure 3.1 Set up for vibration during welding

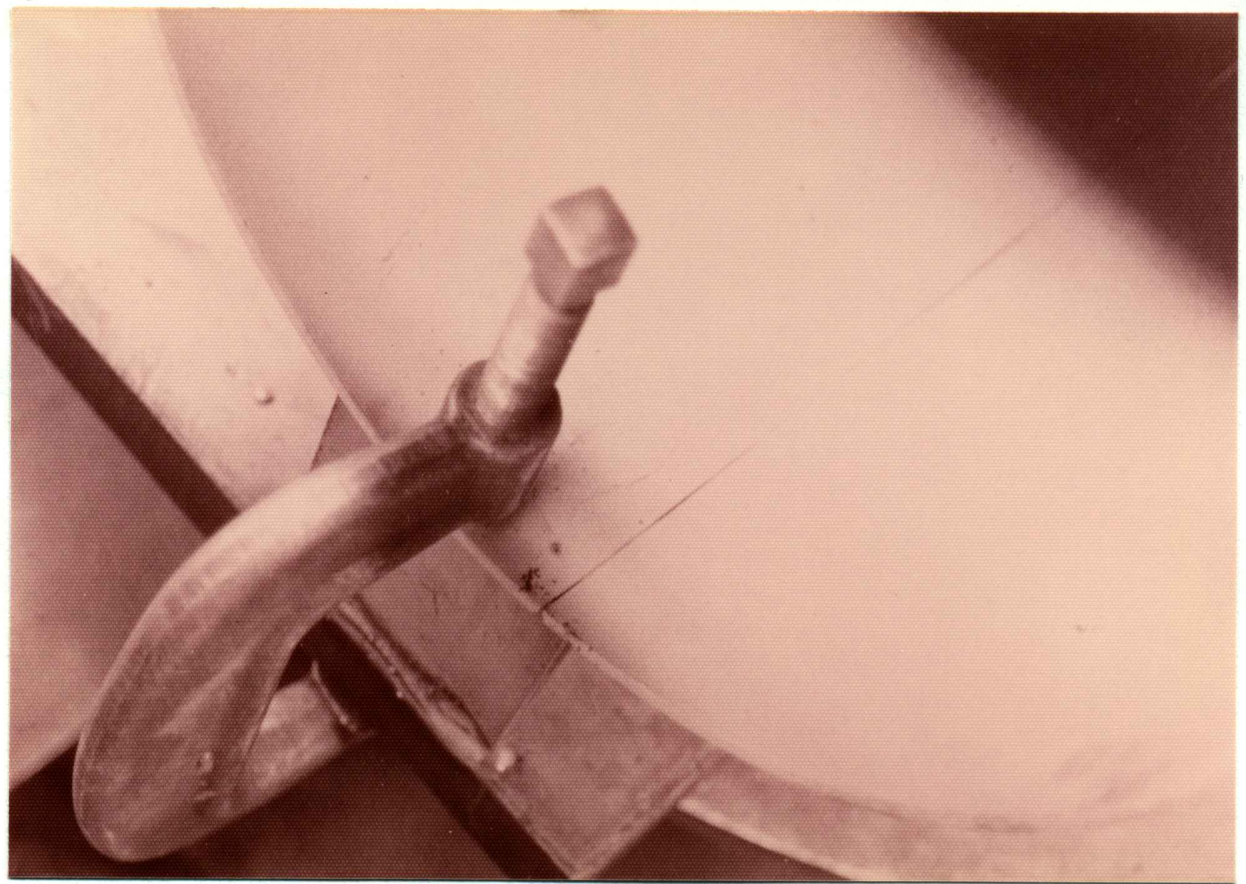

Figure 3.2 Ready for inside weld pass 


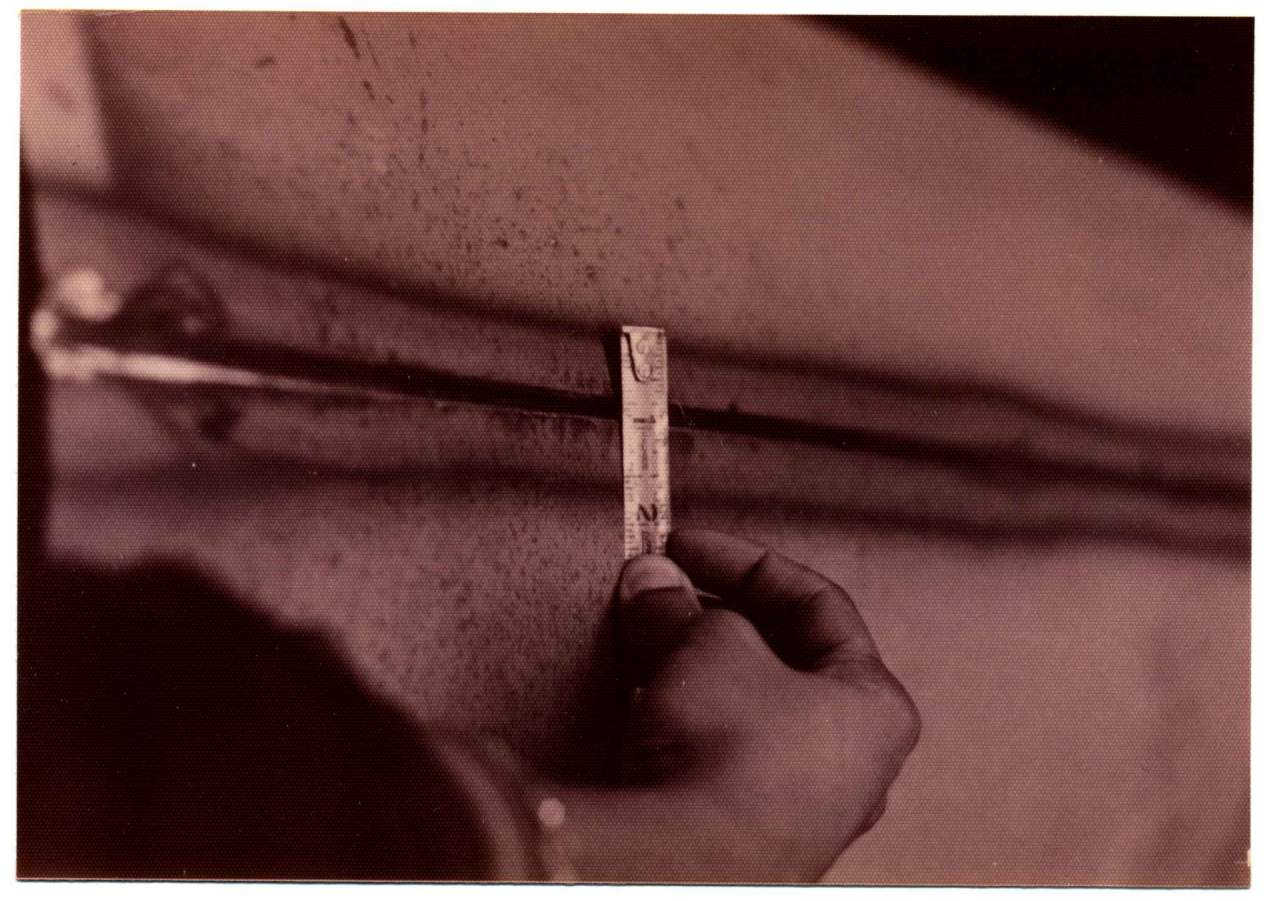

Figure 3.3 Heat affected zone after inside pass and before outside pass

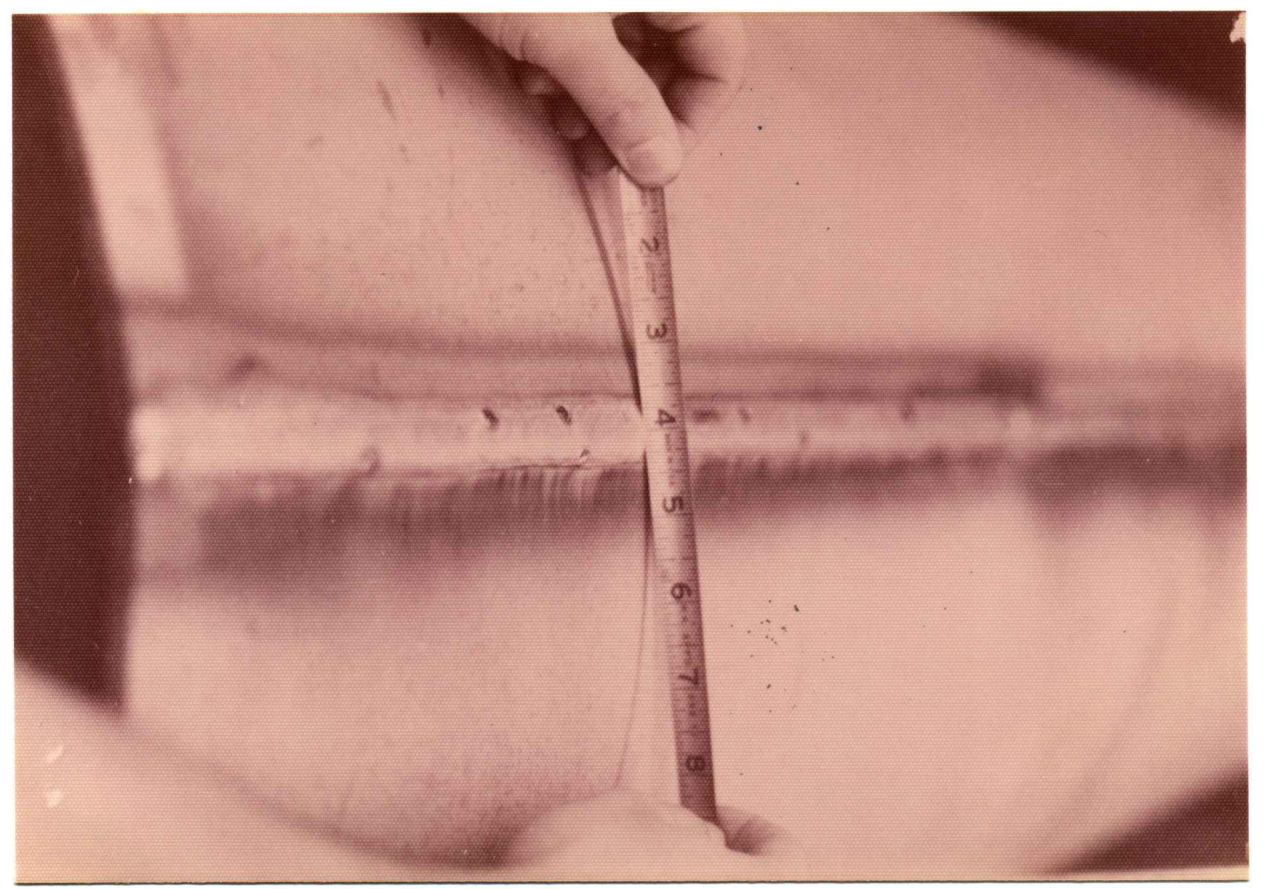

Figure 3.4 Heat affected zone and outside weld 


\subsection{EXPERIMENTAL SET UP (Fig. 3.1-3.4)}

The tube was cold rolled and held in shape by tock welds. It was mounted on a heavy, (approx. 920 lbs) 2.25 inch thick metal base, and clamped onto it at the two edges (see Fig. 3.1). The tube rested on three curved supports, two at the edges and one at the center. These curved supports were rigidly welded onto the base. The vibrator was independently clamped onto this same base, which was isolated from the ground by a large ring shaped rubber pad. The axis of the vibrator was at an angle of $28^{\circ}$ to the longitudinal axis of the tube.

The tube was placed with the seam at the bottom and slightly away from the support. The inside weld pass was made with the tube in this position, and vibrating at 41 cps. The resonance point was at $44 \mathrm{cps}$. The tube was next rotated approx. 1800 , to get the seam at the top and the outside weld was made. The tube was vibrated at $45 \mathrm{cps}$ during the outside pass. The vibration was continued at the resonance frequency of $48 \mathrm{cps}$ for 15 minutes after the weld was completed.

\section{$\mathbf{3 . 3}$ RESULTS}

The residual stresses in this tube were determined by the same method as before. Table IV shows the strains measured at a cross section 22" from the edge, the calibration coefficient used, and the resulting stresses. This set of 
calibration coefficients was used because an identical specimen of the tube material was not available for experimental determination of the coefficients. However, calibration coefficients were determined experimentally using random samples of $A 36$ steel plates (Table $X$ ). The variation in the above results with calibration coefficients is analyzed in chapter four. The longitudinal residual stress distribution is as shown in Fig. 3.5. The data points correspond to the values in Table IV. The curve "before VSR" corresponds to Case 4 discussed in chapter two, and is the stress distribution in a similar tube which had no VSR treatment. 


\section{TABLE IV}

RESIDUAL STRESSES AFTER VSR DURING WELDING

\begin{tabular}{|c|c|c|c|c|c|c|}
\hline \multirow{2}{*}{$\begin{array}{c}\theta \\
\text { (RADIANS) }\end{array}$} & \multicolumn{2}{|c|}{$\begin{array}{c}\text { MEASURED STRAINS } \\
\text { (MICRO STRAINS) }\end{array}$} & \multicolumn{2}{c|}{ CALCULATED STRESSES* } & \multirow{2}{*}{ (KS I $)$} \\
\cline { 2 - 7 } & $\varepsilon_{a}$ & $\varepsilon_{b}$ & $\varepsilon_{c}$ & $\sigma_{L}$ & $\sigma_{T}$ & $\sigma_{y}$ \\
\hline .04 & -161 & +254 & -165 & +62.5 & -12.3 & 1.30 \\
.07 & -88 & +287 & -120 & +51.1 & -19.1 & 1.02 \\
.22 & +162 & +116 & +052 & -15.6 & -17.3 & -.33 \\
.34 & +097 & +065 & +140 & -23.03 & -13.4 & -.48 \\
.39 & +169 & +062 & +120 & -29.6 & -14.8 & -.61 \\
.60 & +074 & +066 & +097 & -14.9 & -11.4 & -.31 \\
.87 & +077 & +065 & +073 & -12.4 & -10.6 & -.25 \\
1.19 & +038 & +049 & +011 & -1.6 & -5.9 & -.03 \\
1.43 & +020 & +061 & +047 & -3.1 & -6.2 & -.07 \\
1.73 & +041 & +090 & +047 & -2.7 & -4.3 & -.05 \\
2.106 & +012 & +043 & +031 & -1.4 & -5.2 & -.03 \\
2.63 & +039 & +031 & +026 & -5.1 & -4.9 & -.10 \\
3.04 & +030 & +050 & +035 & -3.4 & -6.5 & -.07 \\
\hline
\end{tabular}

* $4 A=-1.30 \times 10^{-8}$

$4 B=-2.23 \times 10^{-8}$

$\sigma_{y}=48.2 \mathrm{KSI}$

Gage type EA-06-125RE-120 


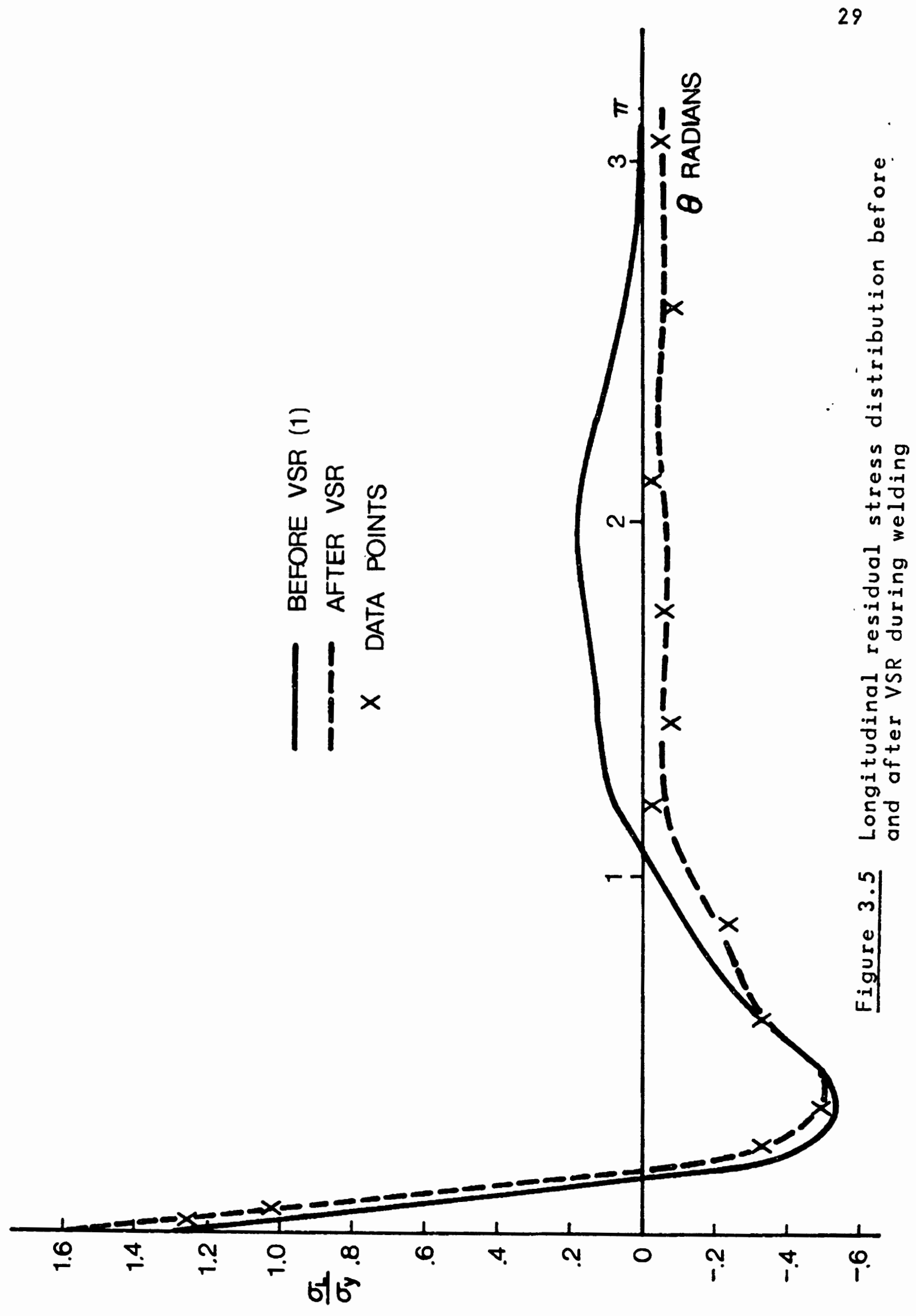




\section{CHAPTER IV}

\section{EQUILIBRIUM CHECK AND ACCURACY OF RESULTS}

In a tube under no external load, the internal stresses must be in static equilibrium. For example, the forces and moments caused by the longitudinal component of the residual stresses on any circular cross section of the tube should satisfy the equilibrium criteria. Therefore, both the summation of internal forces, and the summation of the internal moments, over an entire cross-section must be zero. The computer program used to sum the forces and moments is outlined in Appendix D.

In evaluating the test results as a means of confirming internal stress equilibrium the assumptions listed below have been made. Experimental evidence and past research is quoted to show the extent of validity and accuracy of these assumptions. The assumptions:

(1) "The residual stress field is uniform through the thickness of the tube."

In calculating the forces and moments the residual stress measured on the outside surface is taken as the uniform distribution in the radial direction. Stress measurements from holes on the outside and inside surfaces in a tube of similar dimensions have shown (1) the longitudinal stress distribution to be uniform through the thickness of the tube. This fact has also been substantiated by Tran 
using the proportionality criteria suggested by Kelsey ( 8 ).

(2) "The stress relieved at a hole depth equal to its diameter, represents the total internal stress at that point." It has been demonstrated (1), (9), that $100 \%$ of the strain is relieved by the hole drilling technique, when the hole depth was equal to the hole diameter. However, a question still remains whether all internal stresses (Macro \& Micro) existing at a point are relievable by hole drilling. The above observation may not cause a significant error as Tran (1) reported unbalances in the order of $0.4 \%$ Py and $5.4 \%$ My, for a similar situation but without vibration. (3) "The longitudinal residual stress distribution is symmetric about the weld."

Stress data was obtained only over one half of the tube and these results were assumed to exist over the other half. Test results documented in the latter part of this chapter show that this assumption is well within the accuracy of the hole drilling method. Accuracies in the order of $10 \%$ are claimed (6) for stresses less than .6 yield.

(4) "Stress calculations based on calibration coefficients obtained by experiments on different samples of A36 steel plates, causes only a small error in the equilibrium test."

A test plate of the tube material was not available for calibration experiments. Therefore calibration 
experiments were carried out on three different samples of A36 plates. The variation in the stress distribution is calculated based on these coefficients.

\subsection{EQUILIBRIUM TEST}

A test of summation of forces and moments was done on the stress distribution after VSR during welding. Figure 3.5 shows the distribution of the longitudinal residual stresses on one half of the circular cross section, i.e., a rotation of $\pi$ radians from the weld. The moments have been summed about an axis through the weld and perpendicular to the longitudinal axis of the tube (see Fig. D.2).

The curve was broken into 62 equal segments for the summation. The computer program used and the output is shown in Appendix D, and the results summarized in Table V. Py and My are calculated using a yield stress of 48.2 KSI. This value taken from the mill report, corresponds to the yield stress of the tube material in its plate form.

\subsection{THE EFFECT ON MOMENT BALANCE DUE TO AXIS SHIFT}

To measure the sensitivity of the equilibrium test an attempt was made to find the exact point of balance by varying the stress distribution a constant amount, i.e., moving the horizontal axis downwards in Fig. 3.5. As an example the input data of $\sigma_{L} / \sigma_{y}$ for the first 5 stations on the original distribution were: $1.6,1.2, .72, .25$, 
TABLE V

RESULTS OF EQUILIBRIUM TEST

\begin{tabular}{|c|c|c|c|}
\hline $4 A$ & $4 B$ & $\Sigma P$ & $\Sigma M$ \\
\hline$-1.30 \times 10^{-8}$ & $-2.23 \times 10^{-8}$ & $-.075 \mathrm{Py}$ & $-.116 \mathrm{My}$ \\
\hline
\end{tabular}

$$
\begin{aligned}
& \sigma_{y}=48.2 \mathrm{KSI} \\
& P_{y}=1018.8 \mathrm{Kips} \\
& M y=5407 \mathrm{Kip}-\mathrm{in}
\end{aligned}
$$

TABLE VI

RESULTS OF EQUILIBRIUM TESTS AFTER AXIS SHIFT

\begin{tabular}{|c|c|c|}
\hline$\left(\sigma_{L} / \sigma_{y}\right)$ & $\Sigma P$ & $\Sigma M$ \\
\hline 0 & $-.075 \mathrm{Py}$ & $-.116 \mathrm{My}$ \\
.05 & $-.022 \mathrm{Py}$ & $-.016 \mathrm{My}$ \\
.06 & $-.012 \mathrm{Py}$ & $+.002 \mathrm{My}$ \\
\hline
\end{tabular}


-.14 etc. A downward axis shift of $\Delta \sigma=.05 \sigma L / \sigma_{y}$ would cause the above input data to change to the following: $1.65,1.25, .77, .30,-.09$ etc. The results of the equilibrium tests of the modified stress distributions is summarized in Table VI.

These results indicate an exact point of moment balance for an axis shift in the range $(.05-.06) \sigma_{L} / \sigma_{y}$, and the unbalance in the force is also minimal. The above analysis shows that the unbalance of results in Table $V$ is caused by stresses equivalent to an average compressive stress of approximately 2,500 psi or $5 \%$ of $\sigma_{y}$.

\subsection{CHECK FOR SYMMETRY}

In the equilibrium test results presented in Table $V$ and VI, the unbalance was assumed as double the amount obtained by summing the forces and moments about one half of the cross section.

The stress distribution documented corresponds to stress measurements made on one half of the cross section of the tube (i.e., a rotation of 0 to $\pi$ from weld). The results of the equilibrium test assumes the stress distribution in the other half of the cross section (i.e., a rotation of 0 to - $\pi$ from weld) to an exactly symmetrical about the weld.

Residual stress measurements were made at two points on the second half of the cross section to estimate the accuracy of this assumption. The position of the holes 
TABLE VII

RESULTS OF SYMMETRY CHECK

\begin{tabular}{|c|c|c|c|c|c|}
\hline \multirow{2}{*}{$\begin{array}{c}\theta \\
\text { (RADIANS) }\end{array}$} & \multicolumn{2}{|c|}{$\begin{array}{c}\text { MEASURED STRAINS } \\
\text { (MICRO STRAINS) }\end{array}$} & \multirow{2}{*}{$\begin{array}{c}\sigma_{L} \\
\text { (KSI ) }\end{array}$} & $\sigma_{L} / \sigma_{y}$ \\
\cline { 2 - 4 } & $\varepsilon_{a}$ & $\varepsilon_{b}$ & $\varepsilon_{c}$ & & \\
\hline-.41 & +122 & +047 & +137 & -27.3 & -.56 \\
-1.72 & +065 & +108 & +062 & -5.8 & -.11 \\
\hline
\end{tabular}

$$
\begin{aligned}
& 4 A=-1.30 \times 10^{-8} \\
& 4 B=-2.23 \times 10^{-8}
\end{aligned}
$$




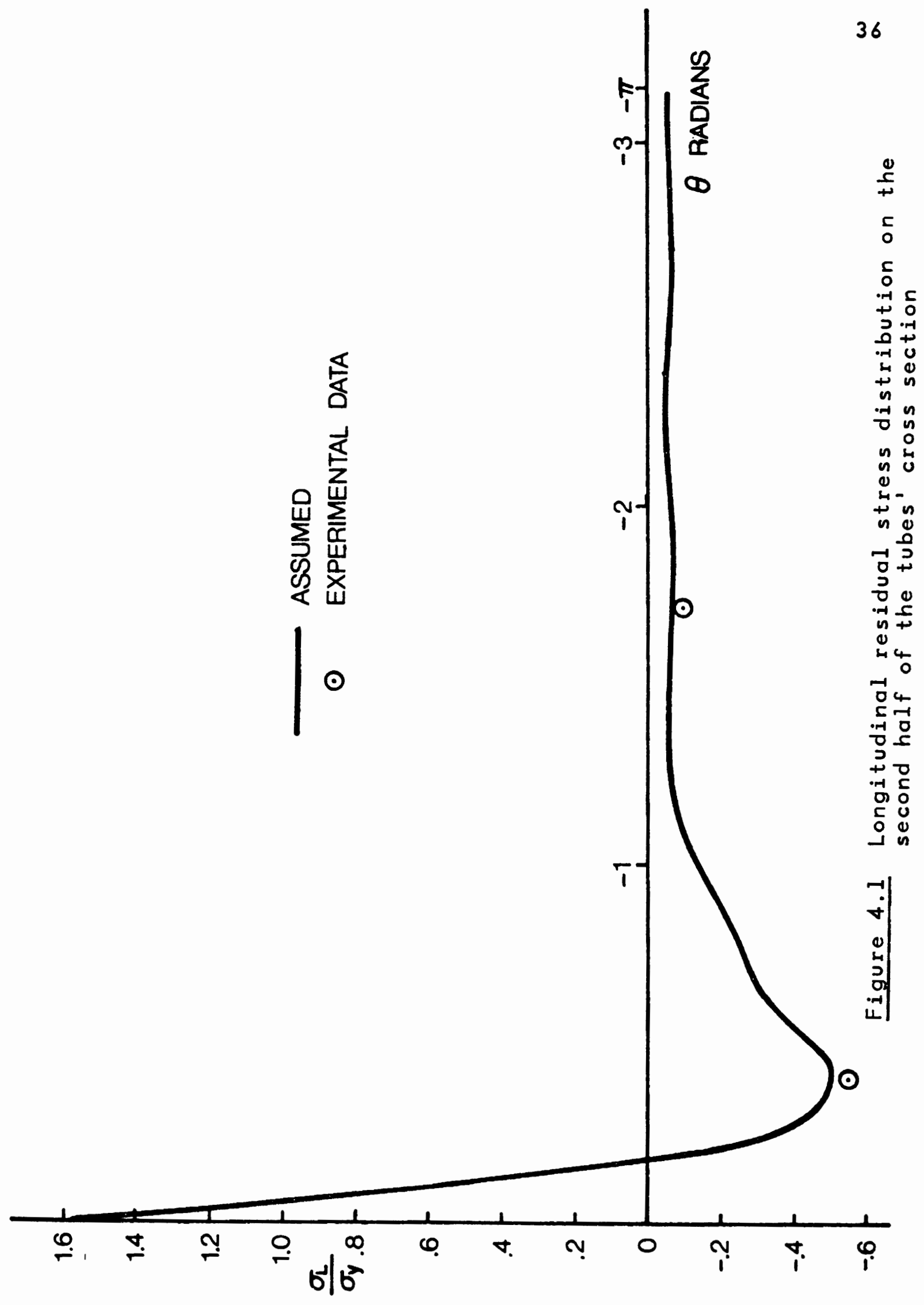


selected correspond to critical points on the assumed stress distribution based on symmetry. The experimental data is shown in Table VII and the results presented in Fig. 4.1.

\subsection{STRESS CHANGES DUE TO VARIATION IN CALIBRATION COEFFICIENTS}

Experiments on test plates were performed by the strain separation method (Appendix C) to obtain calibration coefficients. Three different samples of $A 36$ plates and two gage types of similar dimensions were used. The results of these calibration experiments are given in Tables VIII, IX and $X$. The maximum applied stress was kept below $.6 \sigma y$ to eliminate errors due to local plasticity. The results indicated that in all cases, B was approximately equal to twice $A$. This agrees with the observation made by Rendler and Vigness (10).

The stresses corresponding to the measured strains in Table IV were re-evaluated using the coefficients determined above. The three pairs of coefficients used for this analysis correspond to experiments using gage type 1 . The coefficients used and the resulting stresses are shown in Tables XI and XII. The stresses from Table XII were plotted as a function of rotation from the weld $\theta$. Figure 4.2 shows the change in stress distribution due to different calibration coefficients. The change or "variation" is shown by a stress "envelop" bordered by the maximum and 
TABLE VIII

DETERMINATION OF CALIBRATION COEFFICIENTS

BY THE STRAIN SEPARATION METHOD

EXPERIMENTAL DATA FOR HOLE \#CI

\begin{tabular}{|l|c|c|c|c|}
\hline \multirow{2}{*}{$\begin{array}{l}\text { HOLE } \\
\text { DEPTH } \\
\text { (INCHES) }\end{array}$} & \multicolumn{3}{|c|}{$\begin{array}{c}\text { MEASURED STRAINS } \\
\text { (MICRO STRAINS) }\end{array}$} & \multirow{2}{*}{$\begin{array}{l}\text { APPLIED } \\
\text { LOAD } \\
\text { (KIPS) }\end{array}$} \\
\cline { 2 - 4 } & $\varepsilon a$ & $\varepsilon b$ & $\varepsilon c$ & \\
\hline 0 & 0 & 0 & +2 & 0 \\
0 & -170 & +170 & +606 & 26.75 \\
.025 & -157 & +149 & +566 & 26.75 \\
.050 & -144 & +127 & +489 & 26.7 \\
.075 & -138 & +114 & +440 & 26.7 \\
.100 & -128 & +108 & +415 & 26.8 \\
.112 & -126 & +107 & +409 & 26.8 \\
.125 & -121 & +106 & +402 & 26.7 \\
.135 & -120 & +105 & +402 & 26.75 \\
.135 & -67 & +50 & +195 & 13.4 \\
\hline
\end{tabular}

Plate: 非B, $A-36$

GAGE TYPE: EA-06-125RE-120

CROSS SECTION OF PLATE: 5.38 inch $\times .28$ inch APPROXIMATE DIRECTION OF LOAD: Gage C 


\section{TABLE IX}

DATA FROM CALIBRATION EXPERIMENTS

BY THE STRAIN SEPARATION METHOD

\begin{tabular}{|c|c|c|c|l|c|}
\hline \multirow{2}{*}{$\begin{array}{l}\text { HOLE } \\
\text { REF. }\end{array}$} & \multicolumn{2}{|c|}{$\begin{array}{l}\text { CORRECTED STRAINS* } \\
\text { (MICRO STRAINS) }\end{array}$} & \multirow{2}{*}{$\begin{array}{l}\text { APPLIED } \\
\text { STRESS } \\
\text { (KSI) }\end{array}$} & $\begin{array}{l}\text { APPROX. } \\
\text { DIRECTION } \\
\text { OF.APPLIED } \\
\text { STRESS }\end{array}$ \\
\cline { 2 - 4 } & $\varepsilon_{a}$ & $\varepsilon_{b}$ & $\varepsilon_{c}$ & & $c$ \\
\hline C1 & +062 & -059 & -188 & 18.27 & $c$ \\
C2 & +069 & -067 & -206 & 18.30 & $c$ \\
C3 & +056 & -035 & -165 & 18.30 & $c$ \\
OC1 & -047 & -145 & -050 & 16.74 & $b$ \\
OC2 & -048 & -161 & -060 & 16.74 & $b$ \\
\hline
\end{tabular}

* For computation of corrected strains from measured values refer to Appendix C 
TABLE $X$

RESULTS OF CALIBRATION COEFFICIENTS

OBTAINED FOR DIFFERENT TRIALS

\begin{tabular}{|c|c|c|c|c|}
\hline \multirow[t]{2}{*}{$\begin{array}{l}\text { HOLE } \\
\text { REF. . 非 }\end{array}$} & \multicolumn{2}{|c|}{$\begin{array}{l}\text { CALIBRATION COEFF ICIENT } \\
\left(\text { in }^{2} / 1 b\right)\end{array}$} & \multirow{2}{*}{$\begin{array}{c}\text { PLATE } \\
\sigma_{Y} \\
\text { (KSI) }\end{array}$} & \multirow[t]{2}{*}{$\begin{array}{l}\text { GAGE } \\
\text { TYPE }\end{array}$} \\
\hline & $\begin{array}{c}4 A \\
\left(10^{-8}\right)\end{array}$ & $\begin{array}{c}4 \mathrm{~B} \\
\left(10^{-8}\right)\end{array}$ & & \\
\hline $\mathrm{Cl}$ & -1.38 & -2.74 & 80 & 1 \\
\hline$C 2$ & -1.50 & -3.00 & 80 & 1 \\
\hline$C 2$ & -1.20 & -2.40 & 52 & 1 \\
\hline $\mathrm{OCl}$ & -1.16 & -2.34 & 40.9 & 2 \\
\hline $0<2$ & -1.29 & -2.56 & 40.9 & 2 \\
\hline
\end{tabular}

Gage type $1=E A-06-125 R E-120$

Gage type $2=E A-13-125 R E-120$ 


\section{TABLE XI}

VARIATION OF STRESSES WITH DIFFERENT CALIBRATION COEFFICIENTS

CASE 1: $\quad 4 A=-1.30 \times 10^{-8} ; 4 B=-2.23 \times 10^{-8}$ CASE 2: $\quad 4 A=-1.38 \times 10^{-8} ; 4 B=-2.74 \times 10^{-8}$ CASE 3: $\quad 4 A=-1.50 \times 10^{-8} ; 4 B=-3.00 \times 10^{-8}$ CASE 4: $\quad 4 A=-1.20 \times 10^{-8} ; 4 B=-2.40 \times 10^{-8}$

\begin{tabular}{|c|c|c|c|c|}
\hline \multirow{2}{*}{$\begin{array}{c}\theta \\
\text { (RADIANS) }\end{array}$} & \multicolumn{4}{|c|}{$\sigma_{L}$ FOR CASE \# (KS I) } \\
\cline { 2 - 5 } .04 & +62.5 & +54.0 & +49.5 & +61.9 \\
.07 & +51.1 & +43.6 & +39.9 & +49.9 \\
.22 & -15.6 & -14.9 & -13.7 & -17.0 \\
.34 & -23.0 & -21.1 & -19.4 & -24.2 \\
.39 & -29.6 & -26.7 & -24.8 & -30.9 \\
.60 & -14.9 & -13.8 & -12.7 & -15.9 \\
.87 & -12.4 & -11.6 & -10.7 & -13.3 \\
1.19 & -1.6 & -1.8 & -1.6 & -2.0 \\
1.73 & -2.6 & -3.0 & -2.8 & -3.5 \\
2.11 & -1.4 & -1.5 & -1.4 & -1.8 \\
2.63 & -5.1 & -4.8 & -4.4 & -5.5 \\
3.04 & -3.4 & -3.4 & -3.2 & -3.9 \\
\hline
\end{tabular}




\section{TABLE XII}

VARIATION OF LONGITUDINAL STRESS AS A FRACTION OF THE YIELD STRESS

CASE 1: $\quad 4 A=-1.30 \times 10^{-8} ; 4 B=-2.23 \times 10^{-8}$

CASE 2: $\quad 4 A=-1.38 \times 10^{-8} ; 4 B=-2.74 \times 10^{-8}$

CASE 3: $\quad 4 A=-1.50 \times 10^{-8} ; 4 B=-3.00 \times 10^{-8}$

CASE 4: $\quad 4 A=-1.20 \times 10^{-8} ; 4 B=-2.40 \times 10^{-8}$

\begin{tabular}{|c|c|c|c|c|}
\hline \multirow{2}{*}{$\begin{array}{c}\theta \\
\text { (RADIANS) }\end{array}$} & \multicolumn{5}{|c|}{$\sigma_{L} / \sigma_{y}$ FOR CASE \# } \\
\cline { 2 - 5 } .04 & 1 & 2 & 3 & 4 \\
\cline { 2 - 5 } .07 & +1.30 & +1.12 & +1.03 & +1.28 \\
.22 & -.32 & -.31 & -.28 & -.35 \\
.34 & -.48 & -.44 & -.40 & -.50 \\
.39 & -.61 & -.55 & -.51 & -.64 \\
.60 & -.31 & -.29 & -.26 & -.33 \\
.87 & -.26 & -.24 & -.22 & -.28 \\
1.19 & -.03 & -.04 & -.03 & -.04 \\
1.73 & -.05 & -.06 & -.06 & -.07 \\
2.11 & -.03 & -.03 & -.03 & -.04 \\
2.63 & -.11 & -.10 & -.09 & -.11 \\
3.04 & -.07 & -.07 & -.07 & -.08 \\
\hline
\end{tabular}

$\sigma_{y}=48.2 \mathrm{KSI}$ 

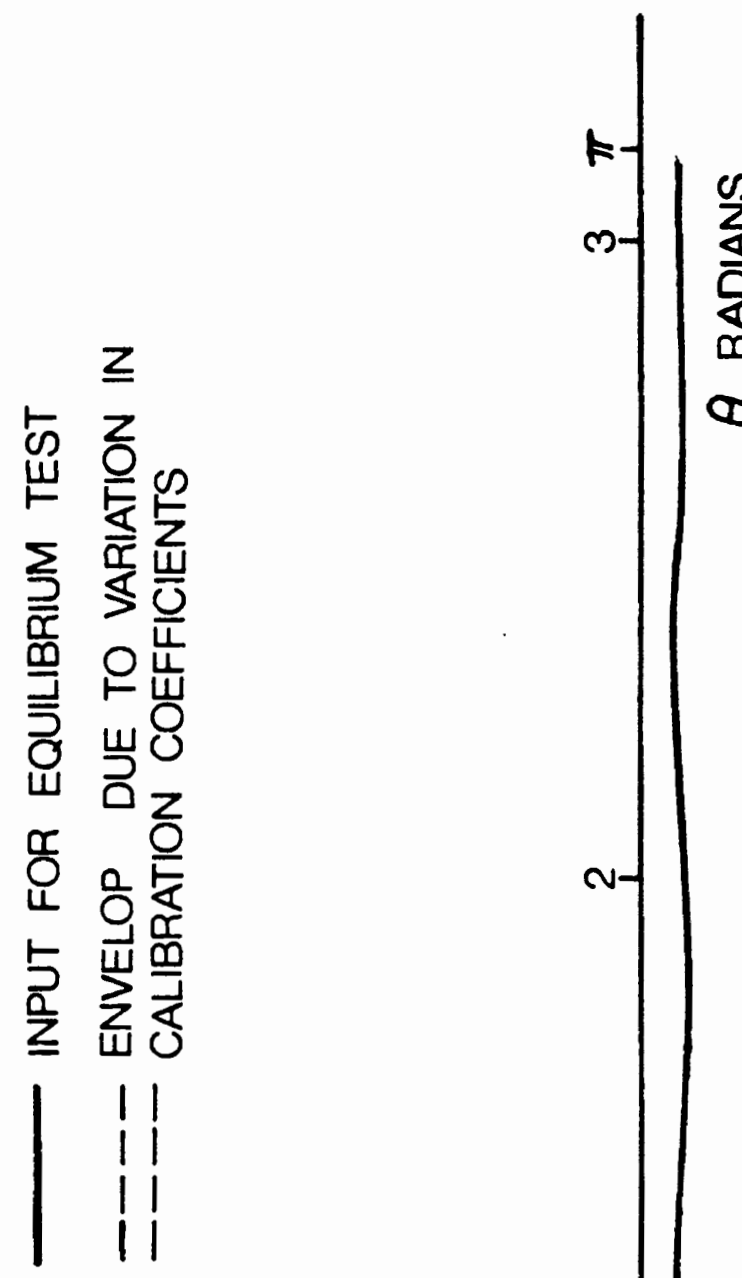

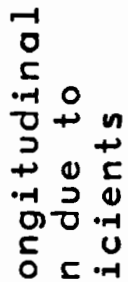
단 (1) 4 ع C

ᄃ 45 - +10 대 070 + o n.-1 - $10 \mathrm{H}$ 440 $0+u$ $+$ 4 당 54 0 0 In 4 o 0 .

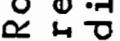

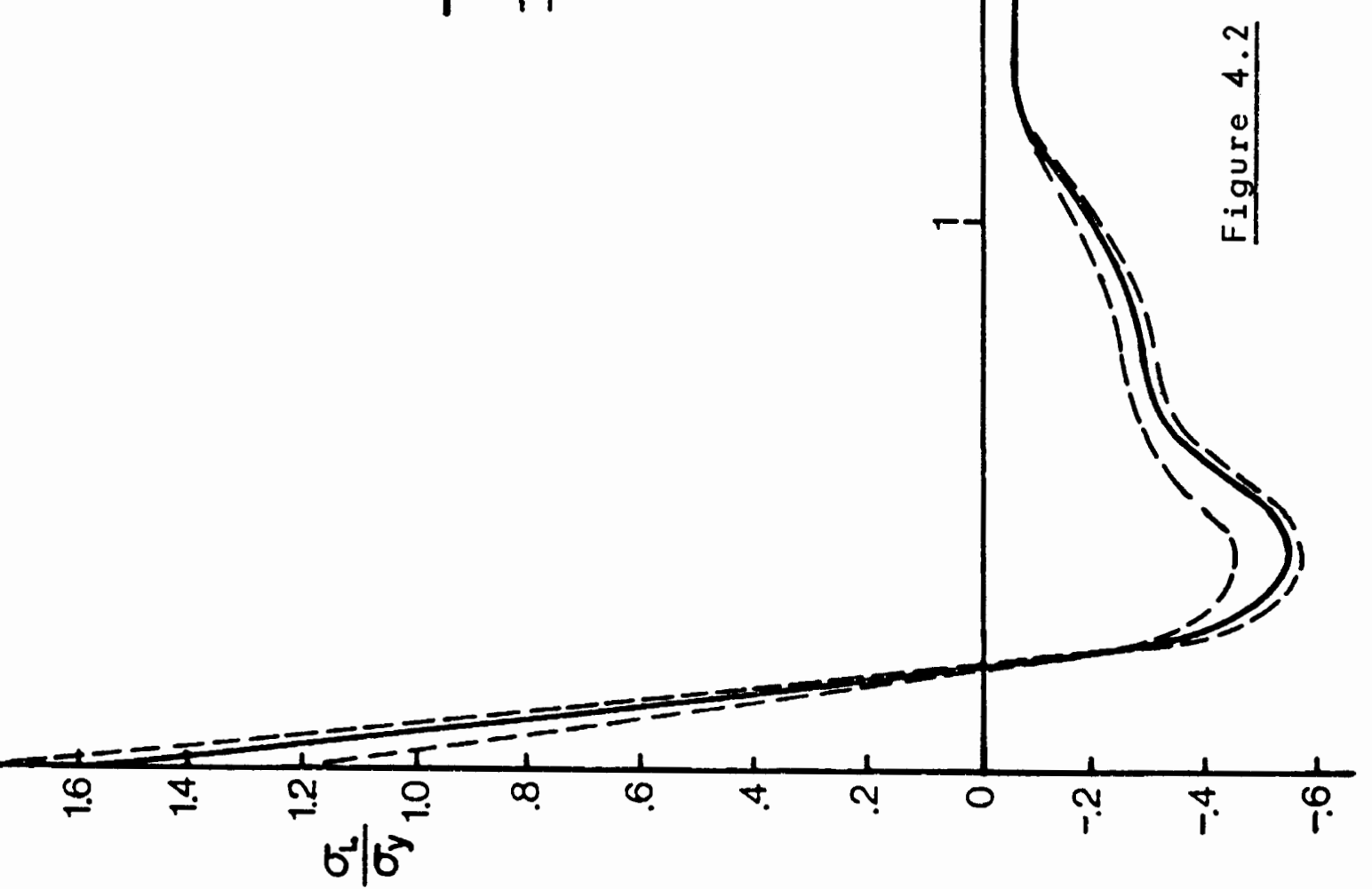


minimum stresses corresponding to each $\theta$. The curve used in the equilibrium test to represent this data is shown for comparison.

\subsection{AN ESTIMATE OF THE ERROR CAUSED \\ IN MEASURING HIGH RESIDUAL STRESSES \\ BY HOLE DRILLING}

A stress of approximately .75 oy was applied on one of the test plates used for the calibration experiment. A hole of a depth equal to its diameter was drilled while the applied stress was maintained constant. Strain meaurements were taken before and after the hole drilling and the results are shown in Table XIII.

Stress calculations were made using these measured strains, based on two different sets of calibration coefficients, experimentally determined for this same plate.

The calculated stresses (Table XIV) were found to hove an error of 10-20\% for an applied stress of 30 KSI (approx. $.75 \sigma y)$. The residual stresses near the weld typically have magnitudes in the order of yield. Therefore stress measurements made by hole drilling adjacent to the weld will have only a very limited accuracy as pointed out by Parlane (6). 
TABLE XIII

EXPERIMENTAL DATA FOR ESTIMATION OF ERROR CAUSED IN MEASURING HIGH RESIDUAL STRESSES BY HOLE DRILLING

\begin{tabular}{|c|c|c|c|c|}
\hline \multirow{2}{*}{$\begin{array}{c}\text { HOLE } \\
\text { DEPTH } \\
\text { ( INCHES ) }\end{array}$} & \multicolumn{3}{|c|}{$\begin{array}{l}\text { MEASURED STRAINS } \\
\text { (MICRO STRAIN) }\end{array}$} & \multirow{2}{*}{$\begin{array}{l}\text { APPLIED } \\
\text { STRESS } \\
\text { (KSI) }\end{array}$} \\
\hline & $\varepsilon_{a}$ & $\varepsilon_{b}$ & ${ }^{\varepsilon_{c}}$ & \\
\hline 0 & 0 & 0 & 0 & 0 \\
\hline 0 & 334 & 991 & 359 & 30.0 \\
\hline .135 & 230 & 676 & 241 & 30.0 \\
\hline $\begin{array}{l}\text { Strain } \\
\text { Relieved }\end{array}$ & -104 & -315 & -118 & 30.0 \\
\hline
\end{tabular}

YIELD STRESS OF PLATE $=40.9$

GAGE TYPE: EA-06-125RE-120

APPROXIMATE DIRECTION OF APPLIED STRESS: $b$

TABLE XIV

ESTIMATE OF ERROR CAUSED IN DETERMINING HIGH RESIDUAL STRESSES BY HOLE DRILLING

\begin{tabular}{|c|c|c|c|c|}
\hline $4 A$ & $4 B$ & $\begin{array}{c}\sigma_{1} \\
(K S I)\end{array}$ & $\begin{array}{c}\sigma_{2} \\
(K S I)\end{array}$ & $\begin{array}{c}\% \text { ERROR } \\
\text { IN } \sigma_{2}\end{array}$ \\
\hline-1.29 & -2.56 & 1.2 & 33.2 & 10.5 \\
-1.16 & -2.34 & 1.7 & 36.6 & 21.9 \\
\hline
\end{tabular}




\section{CHAPTER $V$ \\ SUMMARY, CONCLUSION AND RECOMMENDATION}

Residual stress measurements by the hole drilling method were made on two similar tubes subjected to VSR. The first received VSR after welding, while the second was vibrated during welding. The longitudinal residual stress distributions after VSR were obtained and examined for possible changes in pattern and magnitude of the stresses. An equilibrium check carried out showed the stress distribution obtained to be accurate within the limits accepted for hole drilling. Factors which effect the accuracy of the resulting stresses were discussed in detail in chapter four. A summary of the results of this investigation with conclusions and recommendations will follow in this chapter.

\subsection{SUMMARY OF RESULTS}

The results associated with vibration after welding involved four cases when the vibrator was attached directly onto the tube (Fig. 2.3). Case 1 and Case 4 show residual stresses before vibration. Any difference in Cases 2 and 3 from Coses I and 4, essentially protray the longitudinal residual stress change due to VSR. The difference observed is slight, and hence no significant change due to VSR was 
found. The accepted accuracy of the hole drilling method is in the order of $10 \%$ error for stresses below .60y, and much higher errors for stresses of yield magnitude (6). Therefore the observed change should be of a higher order than the error range to be termed "significant".

The results of the skew vibration shows an increased change in residual stress. Comparison of Fig 2.3 and Fig. 2.5 gives the complete residual stress change caused by vibration after welding. These results are the cumulative effect of vibrations in three directions.

VSR during welding showed the most substantial stress change (Fig. 3.5) observed in this investigation. The data obtained before VSR came from a similar tube welded under normal conditions. The change observed was in the region away from the weld ( $\theta$ greater than 1.1 radians). The residual stresses observed after VSR were compressive, a substantial change from the tensile stresses known $(1,11)$ to exist in this region under normal conditions. From a magnitude standpoint the changes are in the order of 2-3 times a measurement error. However the consistency of the magnitude and compressive nature of the stresses suggest a true change. It should be noted that the sign and magnitude of stresses (in region $\theta$ greater than 1.1) were uneffected by different calibration coefficients (Fig. 4.2). Further, hole drilling has a commonly accepted reliability for stresses of this magnitude. 
Considering the limitations of the stress measurement method and other factors detailed in chapter four, the equilibrium check confirmed the quality of the results. The unbalance in forces and moments was small and was found to be equivalent to a measurement error of $5 \% \sigma y$.

\subsection{CONCLUSIONS}

1. In the case of applying VSR after welding, this investigation did not find a significant residual stress change.

2. VSR during welding appears to offer more promise to affect residual stress. A significant change in residual stress was found in the lower stress area away from the weld.

3. Inconsistencies in the findings of this investigation may be caused by microscopic entanglements as induced by cold forming the tube. Other investigations (4) and manufacturers of VSR equipment (5) warn of the influence of cold working on the success of VSR.

\subsection{RECOMMENDATIONS}

1. Residual stresses of the higher order of magnitude (above .6 oy) typically like those near weld should be studied more closely both before and after VSR by other more accurate stress measurements, e.g., x-ray methods. 
2. Methods and instrumentation should be developed so as to observe the mode shape and amplitude of the vibration. Vibration could thus be controlled to cause maximum energy input.

3. Studies should be made to find the effects of VSR on the fatigue strength of welded components. 


\section{REFERENCES}

1. Tran, C. M., "An Experimental Investigation of the Hole Drilling Technique for Measuring Residual Stresses in Welded Fabricated Steel Tubes," Masters thesis, Portland State University, 1977.

2. Chajes, A., "Principle of Structural Stability Theory," Department of Civil Engineering, University of Massachusetts, 1974.

3. Beedle, L. S., "Plastic Design of Steel Frames," Professor Civil Engineering Fritz Eng. Labs, Dept. of Civil Engineering, Lehigh University, 1974.

4. Cheever, D. L. and E. W. Rowlands, "Vibrotional Conditioning of Castings and Weldments: An exploratory study," Control of distortion and residual stress, Proceedings of International Conference, pg. 22-45, Chicago, IL, Nov. 1976.

5. Martin-Metaltech, "Vibratory Stress Reduction for the Metal Working Industry" - Technical Bulletin of Martin Engineering, 1978.

6. Parlane, A. J.A., "The Determination of Residual Stresses: a review of contemporary measurement techniques, Research engineer, Engineering Department of the Welding Institute.

7. Barrett, Steve, "Effect of Residual Stresses on Steel Tubular Members," Masters thesis, PSU, 1979.

8. Kelsey, R. A., "Measuring Non-Uniform Residual Stresses by the Hole Drilling Method," Aluminum Research Laboratories, New Kensington, PA., 1955.

9. Redner, D., "Measurement of Residual Stresses by Blind Hole Drilling Method," Photolastic Inc., Bulletin TDG-5, revised May 1976.

10. Rendler, N. J. and Vigness, I., "Hole Drilling Strain Gage Method of Measuring Residual Stresses," Shock and Vibration Branch, U.S. Naval Research Laboratory, Washington, D.C. 
11. Chen, W. F. and Ross, D. A., "Tests on Fabricated Tubular Columns," Journal of the Structural Division, Proceedings of ASCE Vol 103, No. ST3, March 1977.

12. "RS-200 Milling Guide, A Precision Optical Alignment and Guide Tool for Measurement of Residual Stresses by the Strain Gage Hole Drilling Method," Photolastic, Inc., Bulletin S-105, 1976 


\section{APPENDIX A}

\section{SUMMARY OF "HOLE DRILLING METHOD" FOR}

DETERMINATION OF RESIDUAL STRESSES

This is a semi-destructive method performed by drilling a shallow hole in a test piece, and measuring the resulting strains. When a small core of material is removed from a stressed object, stresses are disturbed at that point. Strain measurements made around that point indicate the amount of stress relief. The strains are measured using a special rosette of three gages, spaced $45^{\circ}$ apart, and at a mean distance of .202 inches from the center of the hole. Holes are drilled to a depth of .135 inches using a $1 / 8$ inch drill bit. It has been shown (9) that the stresses in the immediate vicinity of the hole are fully relieved when the hole depth is approximately equal to the hole diameter.

Experimental set up and procedure:

The location of the holes are marked on the tube, using a ball point pen. An area of approximately 2" $\times 2$ " is well sanded to receive the rosette. Surface preparation is very important to insure a smooth and firm bond between the rosette and the tube. Sanding is done initially using a coarse grit and then proceeding to finer sanding using silicone carbide paper of 320 grit. A acetone solution is 
applied to get rid of the grease and dirt on the metal surface. It is then cleaned with "Conditioner $A$ " a water based acid surface cleaner. Finally a water based alkaline surface cleaner "Neutralizer 5 " is applied.

The gage rosette mounted on cellophane tape is placed in the desired position. A thin coat of "200 catalyst" is applied on the contact surface of the rosette, lifting one side of the cellophane tape off the tube. The "M-Bond 200 adhesive" is applied over the well dried catalyst and the gage is glued onto the tube. In pasting the gage, a thumb has to be placed on it to squeeze out the excess adhesive and also to provide the warmth required for the catalytic action. The cellophane tape could be removed after about 10 minutes when the bond has set.

The two terminals of each gage are carefully soldered onto a pair of wires connected to the strain indicator. Next the RS-200 milling guide placed on a tripod has to be mounted on the tube above the rosette. The positions of the tripod feet are marked using the template provided. The three adjustable swivel feet are cemented onto the tube surface which has been prepared by coarse sanding and application of acetone solution. "Grip cement" powder mixed with "grip cement liquid" is used for cementing the feet. This cement paste hardens in about 5 minutes and the tripod could then be screwed on. Adjustments are made to level and center the milling guide. Levelling ensures that 
the drill bit is perpendicular to the contact surface resulting in a uniform hole depth. The milling guide is equipped with a microscope attachment and precise centering ( $\pm .001 ")$ can be achieved.

The "milling guide", guides the milling bar which carries the drill bit. The milling bar is equipped with a special micrometer screw adapter to control the hole depth. The drilling was done in increments corresponding to hole depths of .025",.050",.075",.10",.112",.125" and .135". The strain reading at each of the above hole depths was recorded. A systematic variation in the strain reading, indicates good valid results. The strain relaxed at a hole depth of .135 inches is used for the stress computation as shown in Appendix B.

The test procedure outlined above yields fairly consistent results if each step is performed with care. The following points are noteworthy of special attention.

1) A smooth clean surface to place rosette,

2) A $100 \%$ continuous bond between rosette and tube,

3) Firm solder connections between lead wire and gages,

4) Screws on the milling guide should be checked for tightness while drilling, to avoid wabbling and misalignment,

5) Establishing a common ground between the tube and strain indicator equipment eliminates irregular strain readings, 
6) Monitor strain indicator readings after all connections are made before drilling. Unstability and scatter of more than 10 micro strains indicate a potential error. 


\section{APPENDIX B}

\section{COMPUTATION OF STRESSES USING THE DATA OBTAINED FROM THE HOLE DRILLING METHOD}

The magnitude of the strains disturbed when the material in the hole is removed can be measured as explained in Appendix A. The strains are measured using $45^{\circ}$ strain rosette.

\section{Theory and derivation of equations:}

When a hole of a small diameter $\left(2 R_{0}\right)$ is drilled in a region subjected to residual stresses, a strain relaxation occurs. The strains relieved at a point $P$ (Fig. B.l) (at a distance $R$ from the center of the hole) when only one stress $\sigma_{x}$ is present are:

$$
\begin{aligned}
\varepsilon_{r} & =-\sigma_{x}\left(\frac{1+\mu}{2 E}\right)\left(\frac{1}{r^{2}}-\frac{3}{r^{4}} \cos 2 \alpha+\frac{4}{1+\mu} \frac{1}{r^{2}} \cos 2 \alpha\right) \\
\varepsilon_{\theta} & =-\sigma_{x}\left(\frac{1+\mu}{2 E}\right)\left(-\frac{1}{r 2}+\frac{3}{r 4} \cos 2 \alpha-\frac{4 \mu}{r+\mu} \frac{1}{r^{2}} \cos 2 \alpha\right) \\
\gamma r_{\theta} & =\frac{\sigma x}{2 G}\left(\frac{3}{r^{4}}-\frac{2}{r^{2}}\right) \sin 2 \alpha
\end{aligned}
$$

where $r=\frac{R}{R_{0}}$

The radial strain $\varepsilon$ r above could be expressed as:

$$
\varepsilon_{1}=(A+B \cos 2 \alpha) \sigma_{x}
$$

where the coefficients $A$ and $B$ are known functions of $E$, 


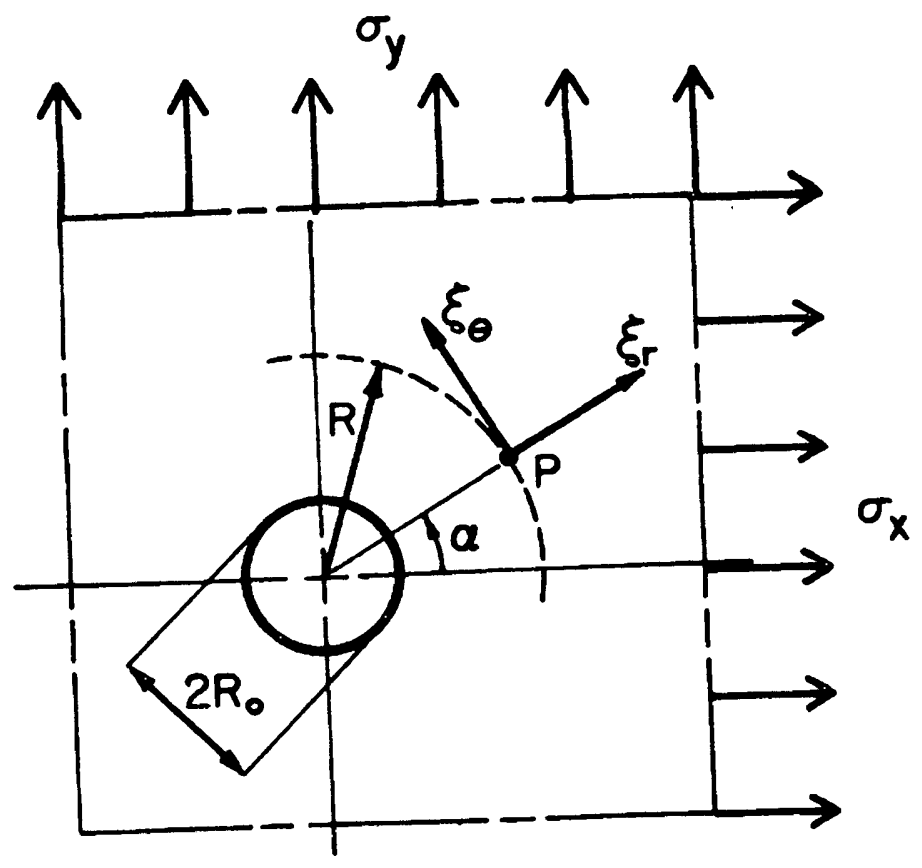

Figure B.I Radial and tangential strains at a point

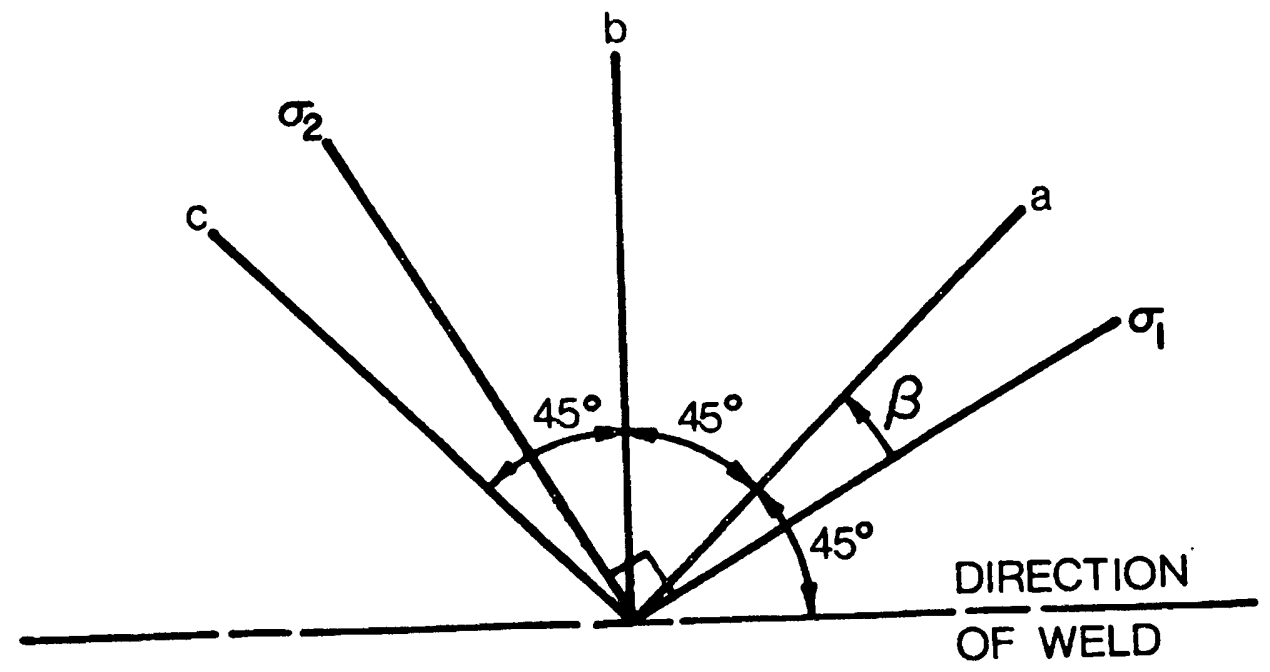

Figure B.2 Position of gages with respect to principal stresses and weld 
$\mu$ and $r$. For a given material and constant $r$ therefore, $A$ and $B$ are constants. The coefficients $A$ and $B$ are determined experimentally as detailed in Appendix $C$. If both stresses $\sigma_{x}$ and $\sigma_{y}$ exist simultaneously Eq. becomes:

$$
\varepsilon_{r}=(A+B \cos 2 \alpha) \sigma_{x}+(A+B \cos 2(\alpha+90)) \sigma_{y}
$$

The three strain gage directions $a, b, c$ with respect to the direction of the longitudinal weld is shown in Fig. B.2. The strain rosette was always placed so that the direction a was $45^{\circ}$ from the weld axis as shown.

The principal stresses are denoted by $\sigma_{1}$ and $\sigma_{2}$. Let the direction of $\sigma_{1}$ be at an angle $B$, to direction $a$, as shown in Fig. B.2. Therefore,

$$
\alpha_{a}=\beta ; \quad \alpha_{b}=\beta+45^{\circ} ; \quad \alpha_{c}=\beta+90^{\circ}
$$

Applying Eq. (2) in directions $a, b$ and $c$ :

$$
\begin{aligned}
& \varepsilon_{a}=(A+B \cos 2 B) \sigma_{1}+(A+B \cos 2(B+90)) \sigma_{2} \\
& \varepsilon_{b}=(A+B \cos 2(B+45)) \sigma_{1}+(A+B \cos 2(B+135)) \sigma_{2} \\
& \varepsilon_{c}=(A+B \cos 2(B+90)) \sigma_{1}+(A+B \cos 2(B+180)) \sigma_{2}
\end{aligned}
$$

Noting that:

$$
\begin{aligned}
& \cos 2(\beta+90)=\cos (2 \beta+180)=-\cos 2 \beta \\
& \cos 2(\beta+180)=\cos (2 \beta+360)=\cos 2 \beta
\end{aligned}
$$




$$
\begin{aligned}
& \varepsilon_{a}=(A+B \cos 2 \beta) \sigma_{1}+(A-B \cos 2 \beta) \sigma_{2} \\
& \varepsilon_{c}=(A-B \cos 2 \beta) \sigma_{1}+(A+B \cos 2 \beta) \sigma_{2}
\end{aligned}
$$

Therefore;

$$
\begin{aligned}
& S=\varepsilon_{a}+\varepsilon_{c}=2 A\left(\sigma_{1}+\sigma_{2}\right) \\
& D=\varepsilon_{a}-\varepsilon_{c}=2 B\left(\sigma_{1}-\sigma_{2}\right) \cos 2 B
\end{aligned}
$$

Solving the above two equations for $\sigma_{1}$ and $\sigma_{2}$ :

$$
\begin{aligned}
& \sigma_{1}=\frac{S}{4 A}+\frac{D}{4 B \cos 2 B} \\
& \sigma_{2}=\frac{S}{4 A}-\frac{D}{4 B \cos 2 B}
\end{aligned}
$$

\section{Proof of expression for $B_{-}$:}

Noting that;

$$
\begin{aligned}
& \cos 2(\beta+45)=\cos (2 \beta+90)=-\sin 2 \beta \\
& \cos 2(\beta+135)=\cos (2 \beta+270)=\sin 2 \beta \\
& \varepsilon_{b}=(A-B \sin 2 \beta) \sigma_{1}+(A+B \sin 2 \beta) \sigma_{2} \\
& \varepsilon_{b}=A\left(\sigma_{1}+\sigma_{2}\right)-B\left(\sigma_{1}-\sigma_{2}\right) \sin 2 \beta
\end{aligned}
$$

Therefore,

$$
\begin{aligned}
\frac{S-2 \varepsilon_{b}}{D} & =\frac{2 A\left(\sigma_{1}+\sigma_{2}\right)-2\left(A\left(\sigma_{1}+\sigma_{2}\right)-B\left(\sigma_{1}-\sigma_{2}\right) \sin 2 \beta\right)}{2 B\left(\sigma_{1}-\sigma_{2}\right) \cos 2 B} \\
& =\frac{2 B \sin 2 B\left(\sigma_{1}-\sigma_{2}\right)}{2 B \cos 2 B\left(\sigma_{1}^{-\sigma}\right)}=\tan 2 \beta
\end{aligned}
$$




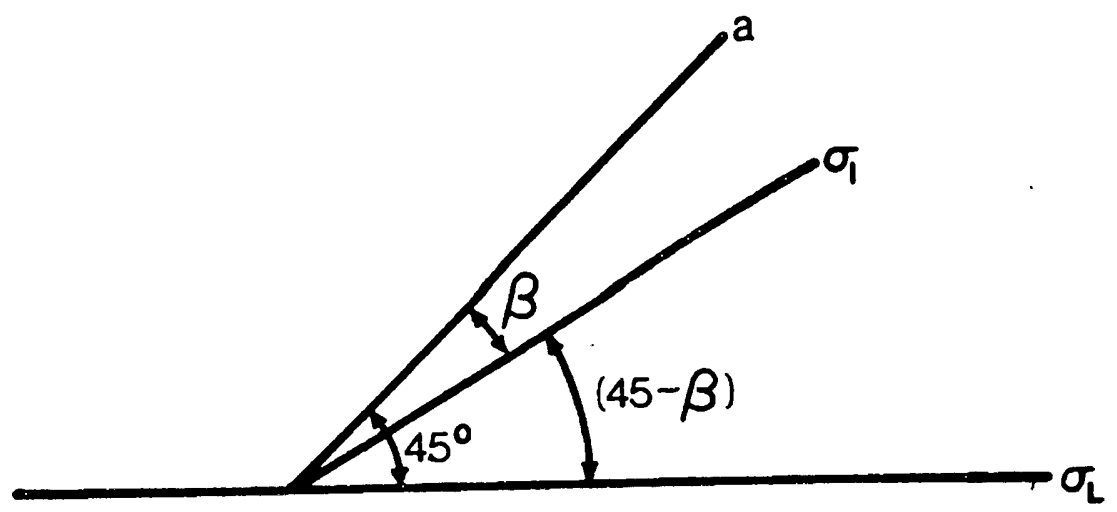

Figure B.3 Location of $\sigma_{L}$ when $\sigma_{l}$ is known

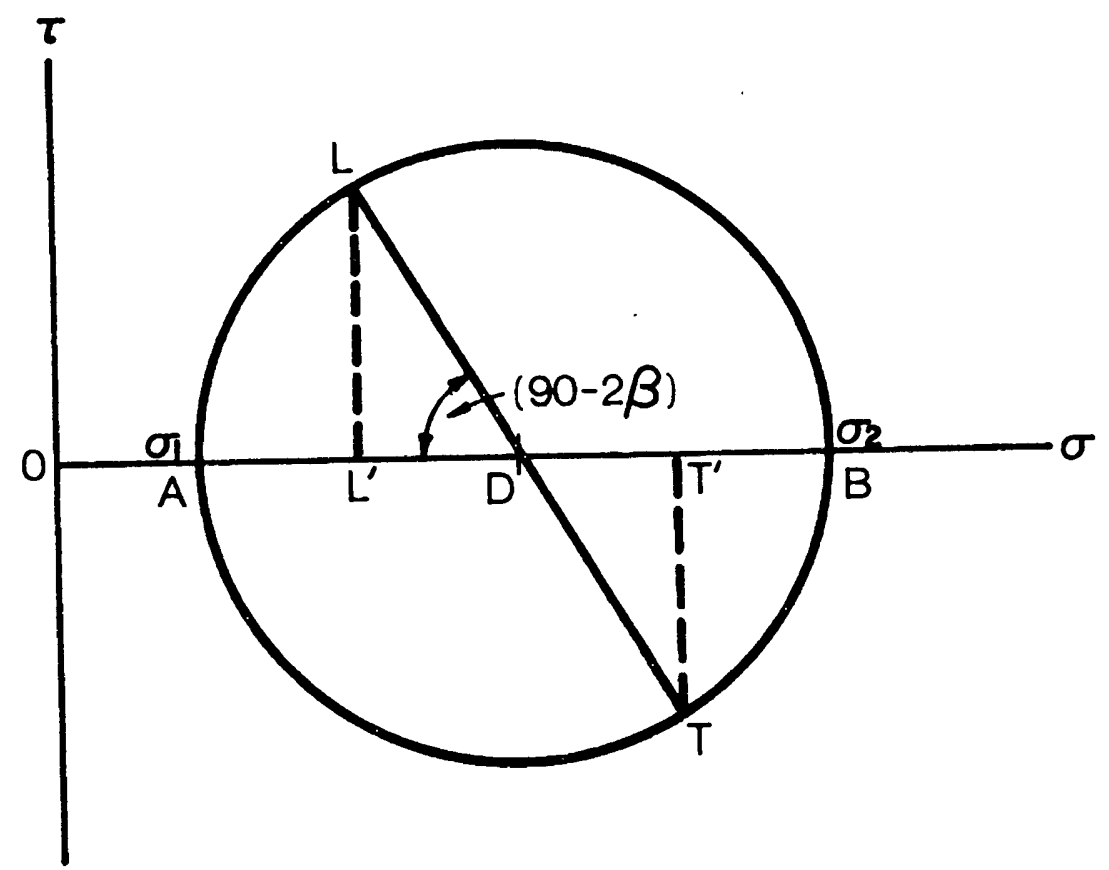

Figure B.4 Mohr's circle

$O D=\frac{\sigma_{1}+\sigma_{2}}{2}$

Radius of Mohr's circle $=R=\frac{\sigma_{2}-\sigma_{1}}{2}$

$\sigma_{L}=O L^{\prime}=O D-R \cos (90-2 B)$

$\sigma_{T}=O T^{\prime}=O D+R \cos (90-2 B)$ 


$$
\frac{S-2 \varepsilon_{b}}{D}=\tan 2 \beta
$$

Principle of Mohr's circle: (Fig. B.4)

The Mohr's circle was used to determine the longitudinal component of the stress $\sigma_{L}$, when the principal stresses $\sigma_{1}$ and $\sigma_{2}$, and their directions were known.

As principal directions by definition have no shear stresses, $\sigma_{1}$ and $\sigma_{2}$ plot on points $A$ and $B$ as shown in Fig. B.4. The angle between the directions of $\sigma_{1}$ and $\sigma_{L}$ is $(45-\beta)^{\circ}$ clockwise (Fig. B.3). Constructing an angle $A D L=(90-2 \beta)$, from $A D$, and point $L$ can be located on the circle. OL' represents the normal stress in the longidudinal direction $\sigma_{L}$. The abscissa of point $T$ diametrically opposite $L$ is the circumferential or transverse stress $\sigma_{T}$. Sample calculation: (Date from Table IV)

A strain rosette type EA-06-125RE-120 was mounted on the second steel tube in the direction shown in Fig. B.2. A hole of .132 inch diameter was drilled to a depth of .135 inches and the strains recorded at the final depth was as follows :

$$
\begin{aligned}
& \varepsilon_{a}=+097 \mu \mathrm{in} / \mathrm{in} \\
& \varepsilon_{b}=+065 \mu \mathrm{in} / \mathrm{in} \\
& \varepsilon_{c}=+140 \mu \mathrm{in} / \mathrm{in}
\end{aligned}
$$

The calibration coefficients used:

$$
4 A=-1.30 \times 10^{-8} ; \quad 4 B=-2.23 \times 10^{-8}
$$


using Eq. (3) and (4)

$$
\begin{aligned}
& S=\varepsilon_{a}+\varepsilon_{c}=97+140=237 \mu \text { in } / \text { in } \\
& D=\varepsilon_{a}-\varepsilon_{c}=97-140=-43 \mu \text { in } / \text { in } \\
& \tan 2 B=\frac{S-2 \varepsilon_{b}}{D}=\frac{237-2(65)}{-43} \\
& 2 B=-68.1^{\circ} \\
& \sigma_{1}=\frac{S}{4 A}+\frac{D}{4 B \cos 2 B} \\
&=\frac{237 \times 10^{-6}}{\left(-1.30 \times 10^{-8}\right)}+\frac{(-43)}{\left(-2.23 \times 10^{-8}\right) \cos \left(-68.1^{\circ}\right)} \\
&=-18230.7+5171.9 \\
&=-13059 \mathrm{psi} \\
& \sigma_{2}=\frac{S}{4 A}-\frac{D}{4 B \cos 2_{B}}=-23402 \mathrm{psi} \\
&
\end{aligned}
$$

using (5), from Mohr's circle:

$$
\begin{aligned}
& O D=\frac{\sigma_{1}+\sigma_{2}}{2}=\frac{-13059-23402}{2}=-18230 \\
& R=\frac{\sigma_{2}-\sigma_{1}}{2}=\frac{-23402+13059}{2}=-5171 \\
& (90-2 \beta)=(90+68.1)=158.1^{\circ} \\
& \sigma_{L}=-18230-(-5171) \cos \left(158.1^{\circ}\right)=-23,027 \mathrm{psi} \\
& \sigma_{T}=-18230+(-5171) \cos (158.1)=-13,433 \mathrm{psi}
\end{aligned}
$$

The computer program used to perform the above calculations, 
and the computer output for the above problem are shown on the following pages. 
COMPUTER PROGRAM FOR CALCULATING PRINCIPAL, LONGITUDINAL AND CIRCUMFERENTIAL STRESSES FROM HOLE DRILLING DATA

LI SHANTI

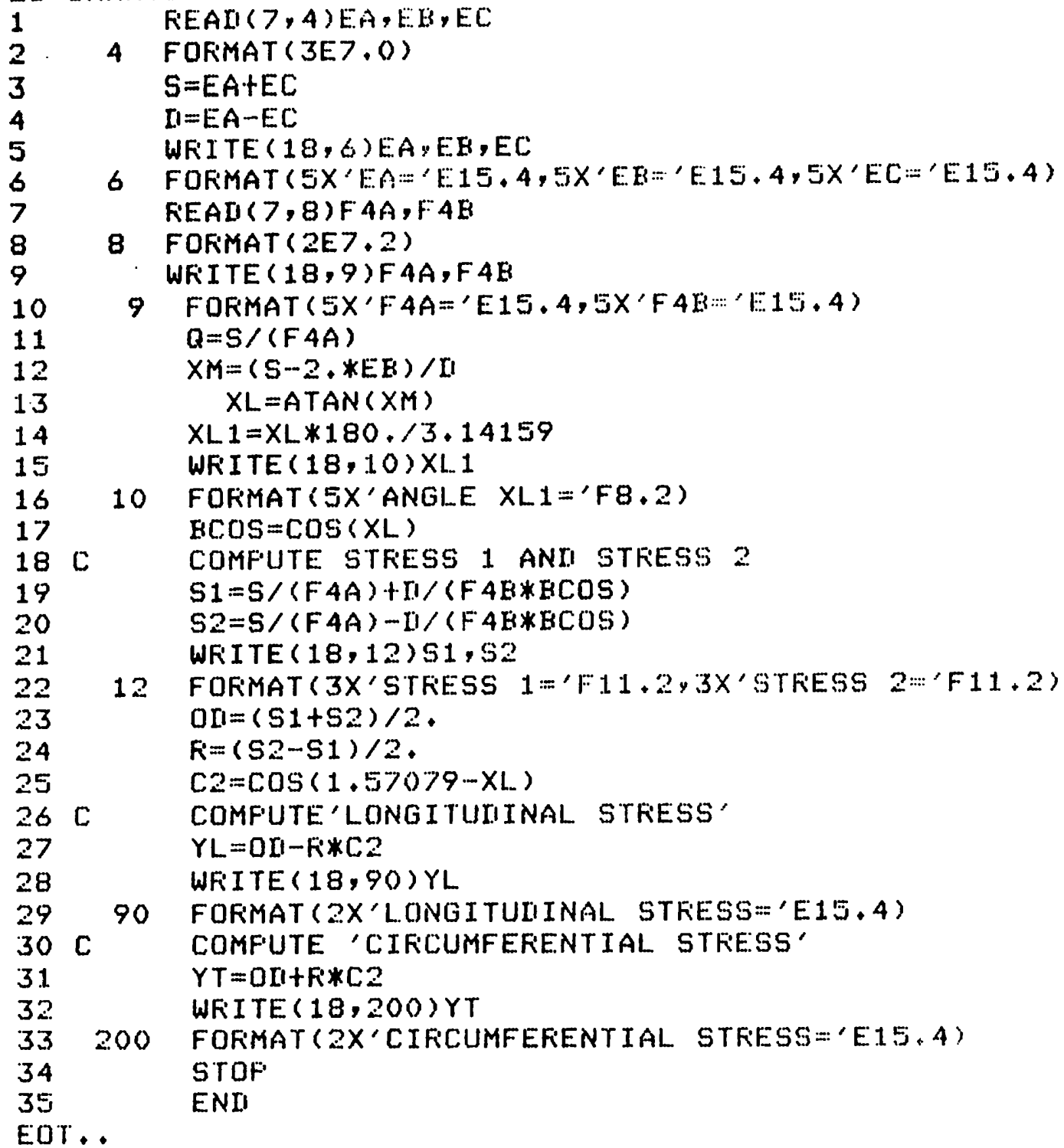


포

$r_{3}$
0
1
0
0
0
0
0

i)

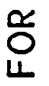

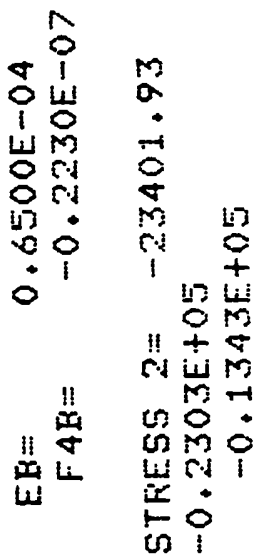

$\sum_{4}$

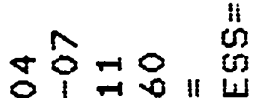

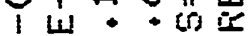

wo 0 a w

890 1

a. ME $\frac{1}{\sigma}$

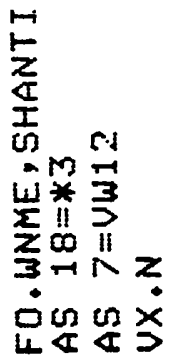

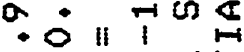

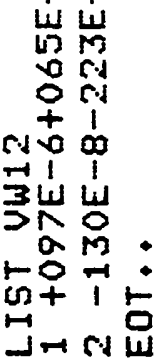

- $\frac{1}{x} \| \frac{\pi}{z}$

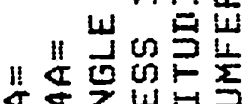

山ᄂ 4 is 0

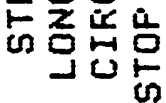




\section{APPENDIX C}

THE STRAIN SEPARATION METHOD FOR EXPERIMENTAL DETERMINATION OF CALIBRATION COEFFICIENTS

A calibration process consists of applying a known stress on a test specimen and measuring the resulting strains. The known stress and strain values are then used to establish calibration coefficients. These coefficients thus obtained can be used to calculate unknown stresses when the relieved strains due to hole drilling are known.

The change in strain introduced by drilling a hole in a test piece under load, is a function of both the unknown and the applied stresses. In the strain separation method the strain caused by these two types of stresses can be separated. The strain component due only to the applied load can be computed and used in determining the calibration coefficient. Residual stresses in the material and stresses caused by drilling constitute the "unknown stresses."

Theory and Procedure of Strain Separation

The test was performed on a mild steel plate (24" $x$ 6"), using a $1 / 8$ inch gage rosette. The specimen was loaded to a stress of $18.27 \mathrm{ksi}$, and o hole was drilled in increments to a depth of .135 inches. The total strain $\left(\varepsilon_{T}\right)$ relieved at this stress is given by: 


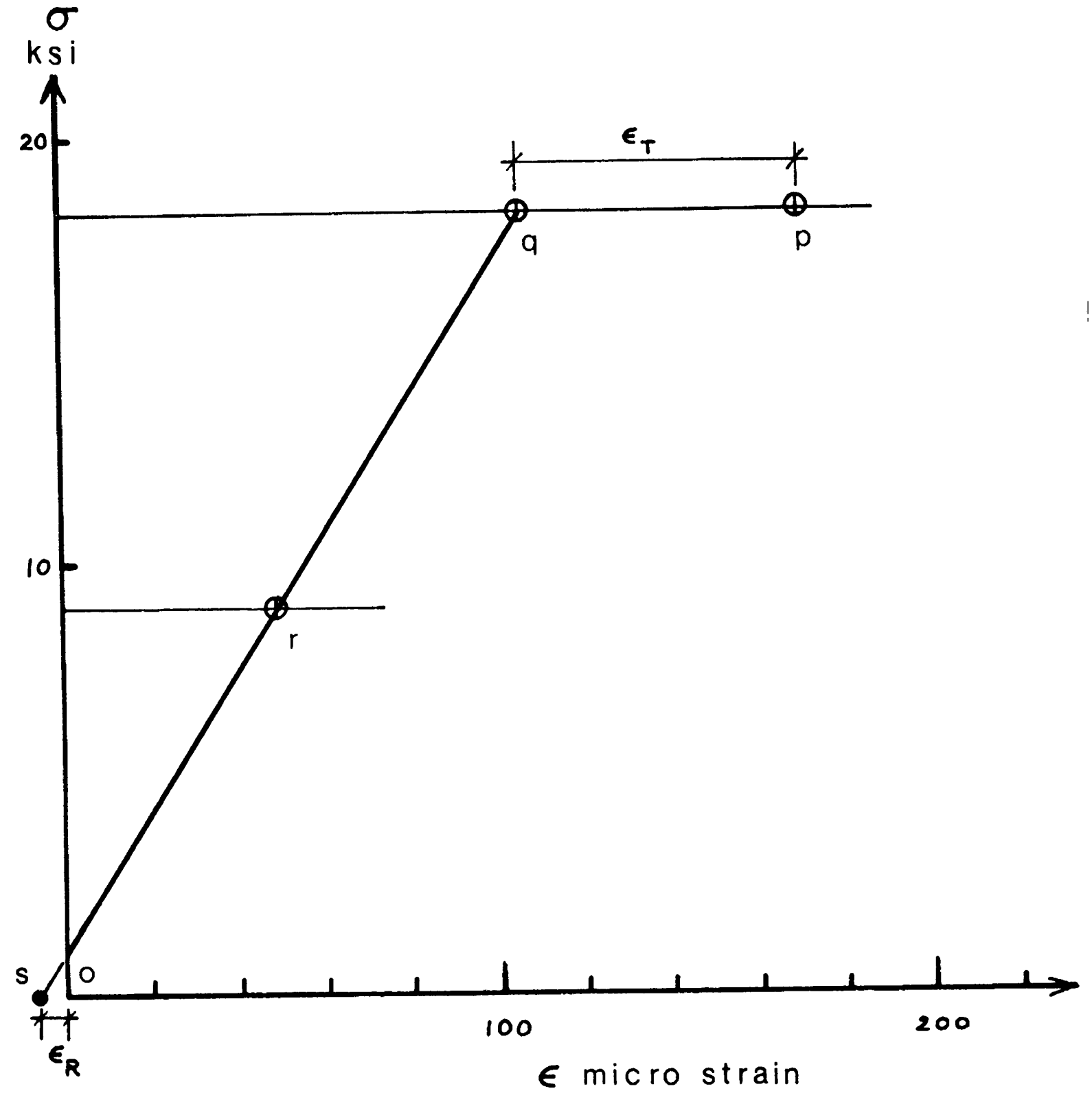

Figure C.I Example of graphical interpolation used in strain separation 


$$
\varepsilon_{T}=\varepsilon_{q}-\varepsilon_{P} \quad(\text { Fig. C.1) }
$$

The load was decreased to a stress of $9.15 \mathrm{ksi}$, and the strain $\varepsilon_{r}$ was noted. Graphical extrapolation of the stress-strain curve qr, to the zero strain axis at $s$, pro$v i d e s \varepsilon_{s}$. The strain corresponding to a zero applied load is, $\varepsilon_{0}$ before drilling and $\varepsilon_{s}$ ofter drilling. The difference $\varepsilon_{R}=\varepsilon_{s}-\varepsilon_{0}$, therefore represents the strain relaxed due to the "unknown" loads.

Total strain relief due to hole $=\varepsilon_{T}$

Component of strain caused by unknown stress $=\varepsilon_{R}$ strain relief due to applied stress $=\left(\varepsilon_{T}-\varepsilon_{R}\right)$

Calculation of Calibration Coefficients Using Data from Strain Separation

From Appendix B

$$
\begin{aligned}
& \sigma_{1}=\frac{S}{4 A}+\frac{D}{4 B \cos 2 B} \\
& \sigma_{2}=\frac{S}{4 A}-\frac{D}{4 B \cos 2 B} \\
& \tan 2 B=\frac{S-2 \varepsilon_{b}}{D}
\end{aligned}
$$

where $S=\varepsilon_{a}+\varepsilon_{c}$

$$
D=\varepsilon_{a}-\varepsilon
$$

Addition of Eqs. (3.1) and (3.2) gives,

$$
\sigma_{1}+\sigma_{2}=\frac{2 S}{4 A}
$$




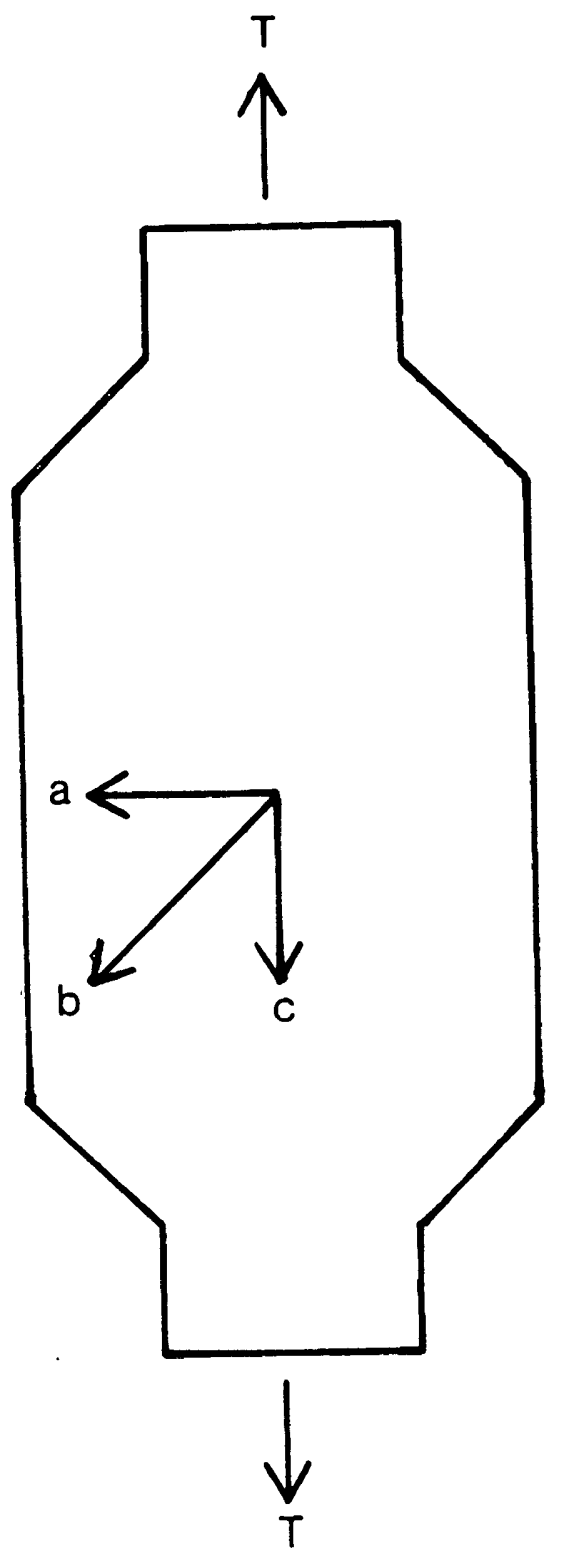

Figure C.2 Orientation of gages on test plate 


$$
4 A=\frac{2 S}{\left(\sigma_{1}+\sigma_{2}\right)}
$$

The difference of Eq. (3.1) and (3.2) gives,

$$
\begin{aligned}
\left(\sigma_{1}-\sigma_{2}\right) & =\frac{2 D}{4 B \cos 2 \beta} \\
4 B & =\frac{2 D}{\left(\sigma_{1}-\sigma_{2}\right) \cos 2 B}
\end{aligned}
$$

Eqs. (3.4) and (3.5) give the calibration coefficients $4 A$ and $4 B$ when the applied stresses $\sigma_{1}$ and $\sigma_{2}$ and the corresponding strains $\varepsilon_{a^{\prime}} \varepsilon_{b}$ and $\varepsilon_{c}$ are known.

Sample Calculation: (Data from Table VIII)

A strain rosette type Ea-06-125RE-120 was mounted on a steel plate (cross section $5.38 \times .28^{\prime \prime}$ ) in the direction shown in Fig. C.2. A strain separation experiment gave the following data.

\begin{tabular}{|l|c|c|c|c|}
\hline $\begin{array}{l}\text { HOLE } \\
\text { DEPTH } \\
\text { (INCHES) }\end{array}$ & $\varepsilon_{a}$ & $\varepsilon_{b}$ & $\varepsilon c$ & $\begin{array}{c}\text { LOAD T } \\
\text { (KIPS) }\end{array}$ \\
\hline 0 & -170 & +170 & +604 & 26.75 \\
.135 & -120 & +105 & +402 & 26.75 \\
.135 & -67 & +50 & +195 & 13.4 \\
\hline
\end{tabular}

$$
\text { applied stress }=\frac{26.75}{5.38 \times .28}=18.27 \mathrm{ksi}
$$


TABLE XV

CALCULATION OF CORRECTED STRAIN

\begin{tabular}{|c|c|c|c|c|}
\hline $\begin{array}{l}\text { HOLE } \\
\text { DEPTH }\end{array}$ & $\varepsilon_{a}$ & $\varepsilon_{b}$ & $\varepsilon_{c}$ & $\begin{array}{c}\sigma_{1} \\
(K S I)\end{array}$ \\
\hline 0 & -170 & +170 & +604 & 18.27 \\
\hline .135 & -120 & +105 & +402 & 18.27 \\
\hline .135 & -67 & +50 & +195 & 9.15 \\
\hline$\varepsilon T$ & 50 & -65 & -202 & \\
\hline$\varepsilon R$ & -12 & -6 & -14 & \\
\hline $\begin{array}{l}\text { Corrected } \\
\text { Strain }\end{array}$ & +62 & -59 & -188 & \\
\hline
\end{tabular}


For direction b:

$$
\varepsilon_{T}=105-170=-65 \mu \mathrm{in} / \mathrm{in}
$$

From graphical interpolation (Fig. C.I)

$$
\begin{aligned}
& \varepsilon_{R}=-6 \mu \mathrm{in} / \mathrm{in} \\
& \varepsilon_{b} \text { (due to applied load only) }=-65-(-6)=-59 \mu \mathrm{in} / \mathrm{in}
\end{aligned}
$$

Similarly the corrected strain in the $a, b, c$ directions are: (Table XV) $\varepsilon_{a}=+62, \varepsilon_{b}=-59, \quad \varepsilon_{c}=-188$

$$
\begin{aligned}
& S=+62-188=-126 \mu \mathrm{in} / \mathrm{in} \\
& D=+62-(-188)=+250 \mu \mathrm{in} / \mathrm{in}
\end{aligned}
$$

Eq. (3.3) gives $\tan 2 \beta=\frac{-126-2(-59)}{250}$

$$
2 \beta=-1.83^{\circ}
$$

As $\beta$ is the angle between direction $a$, and $\sigma_{1}$ by definition, for $\beta \simeq 0 \quad \sigma_{1}=0$ and $\sigma_{2}=18,270 \mathrm{psi}$

Eq. (3.4) gives:

$$
4 A=\frac{2 *\left(-126 \times 10^{-6}\right)}{18270}=-1.38 \times 10^{-8} \mathrm{in}^{2} / 1 \mathrm{~b}
$$

Eq. (3.5) gives:

$$
4 B=\frac{2^{*}\left(250 \times 10^{-6}\right)}{-18270 \cos (-1.83)}=-2.74 \times 10^{-8} \mathrm{in}^{2} / 1 \mathrm{~b}
$$




\section{APPENDIX D}

COMPUTER PROGRAM FOR SUMMATION OF FORCES AND MOMENTS

It is required to find the total force, and the moment of this force about an axis, when the stress distribution over the cross section of the tube is known. The problem is to find the area, center of gravity and first moment of area about a selected axis, for segments under a general curve. The method used is linear approximation of segments of the curve.

The tangent to the circular cross section at the point of the weld was selected as the moment axis. The sign convention used was:

Tensile stresses positive

Compressive stresses negative

Clockwise moments positive

Counter-clockwise moments negative

The above expression for area (force) and moment are for the case of the shaded element shown. There are really several cases that must be accounted for if the program is to handle all possible cases of slope and axis interception of the given curve. The areas and centers of gravity for the elements in the different cases are calculated in a similar manner and are summarized in a flow chart 
(Fig. D.3). The expression for area and center of gravity for each case can be found in the attached computer program against the statement number indicated in the flow chart.

\section{Input Data for Computer Program}

The input data was obtained from the curve shown in dashed lines in Fig. 3.5. This curve gives the distribution of the longitudinal residual stresses on one half of the circular cross section (i.e., a rotation of $\pi$ radians from the weld). The curve was divided into 62 equal increments. The ordinates $\frac{\sigma_{L}}{\sigma_{y}}$ corresponding to .05 radian increments of the abscissa were read off the curve, and are listed in lines 3 thru 65 on the input data. The other information provided were (line 2 ), the number of segments in a quarter circle, the outer diameter and wall thickness of tube, the distance from weld to the moment axis, and the Youngs modulas and yield stress of the tube material.

\section{Results from Computer Output}

The output tabulated the area, lever arm and the sum of forces and moments in the 62 elements considered. The final sum of forces and moments given at the bottom are for half of the cross section. 


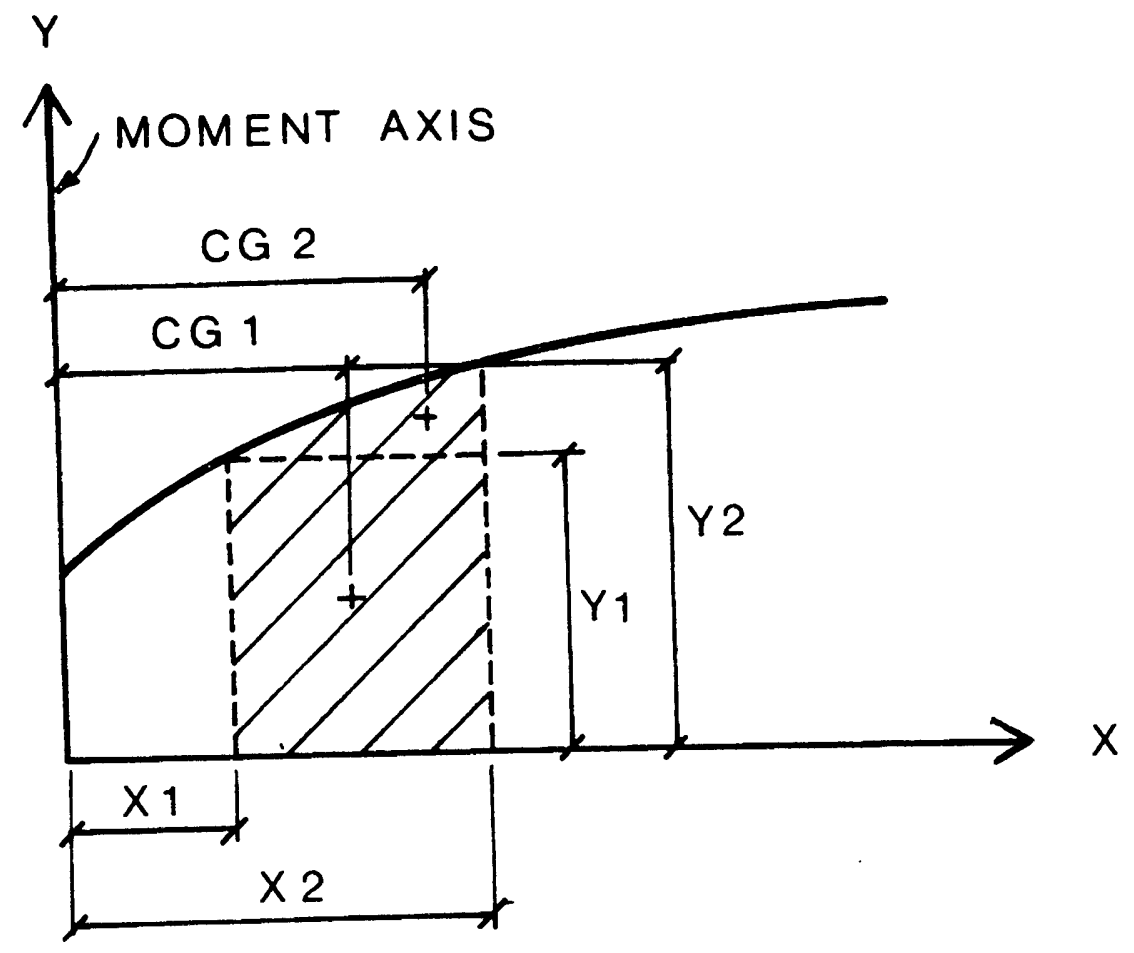

Figure D.1 General element of curve

Considering the shaded element in the general curve in Fig. D.I

$Y_{1}=$ first ordinate of element

$Y_{2}=$ second ordinate of element

$x_{1}=$ first abscissa of element

$x_{2}=$ second abscissa of element

CGI = $X$ distance from moment axis to center of gravity of Area $l$

CG2 = $x$ distance from moment axis to center of gravity of Area 2

Area $1=\left(x_{2}-X_{1}\right) \quad y_{1}$

$\operatorname{cGl}=x_{1}+\frac{\left(x_{2}-x_{1}\right)}{2}=\frac{x_{1}+x_{2}}{2}$ 
Area $2=\frac{\left(X_{2}-X_{1}\right)\left(Y_{2}-Y_{1}\right)}{2}$

$\operatorname{cG2}=x_{1}+\frac{2}{3}\left(x_{2}-x_{1}\right)=\frac{x_{1}+2 x_{2}}{3}$

Now since this is a tube the $X$ coordinate can be thought of as an arc length.

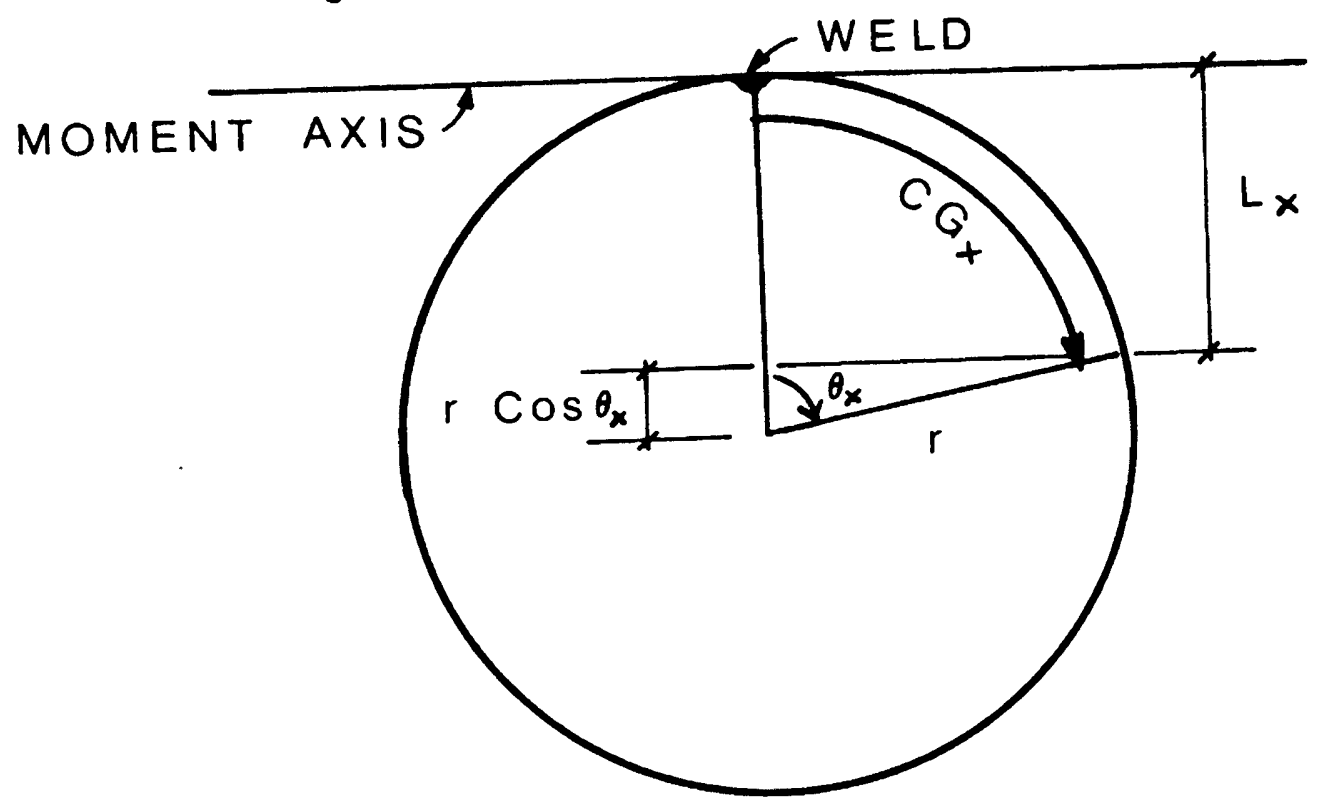

Figure D.2 Cross section of tube

Referring to Fig. D.2:

$$
\begin{aligned}
& \theta_{x} \text { (Radians) }=\frac{C G_{x}}{r} \\
L_{x}= & \text { lever arm to } C G_{x}=r\left(1-\cos \theta_{x}\right) \\
M= & \text { moment of shaded area } \\
= & \text { Area } 1 * r\left(1-\cos \frac{C G_{1}}{r}\right) \\
& + \text { Area } 2 * r\left(1-\cos \frac{C G_{2}}{r}\right)
\end{aligned}
$$




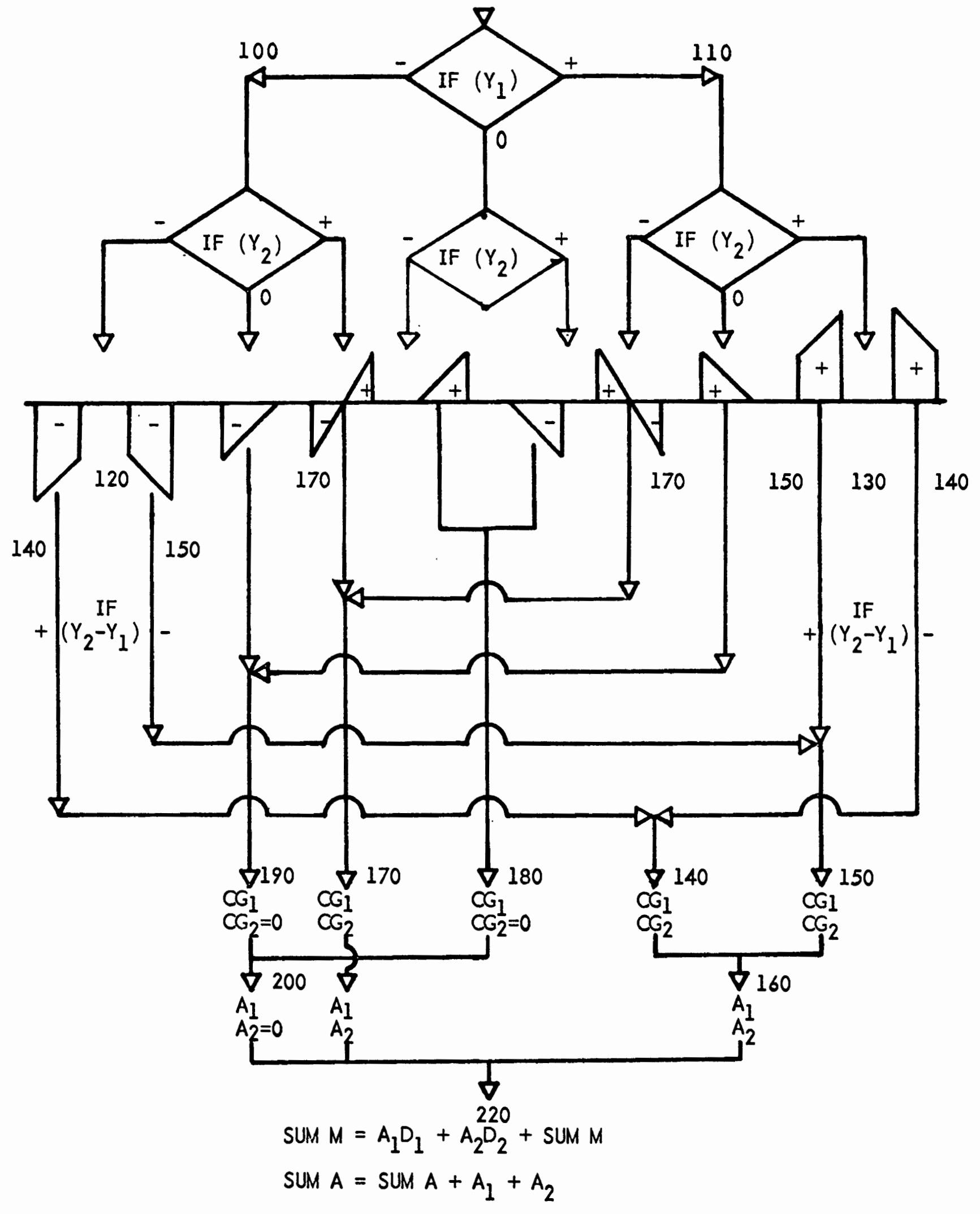

Figure D.3 Flow chart (7) 


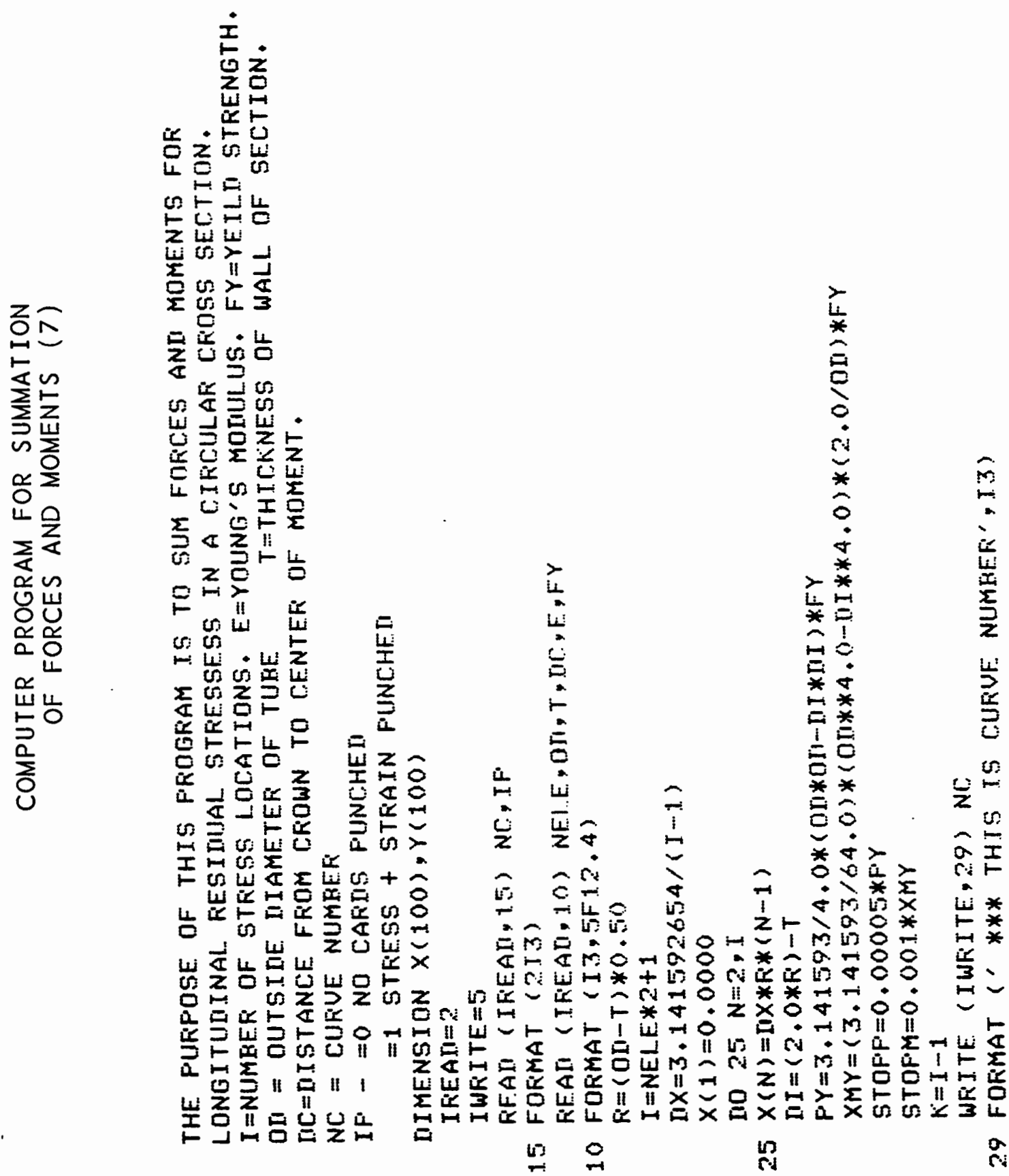

迹

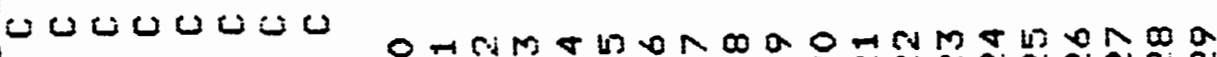
Harma 
\begin{tabular}{l}
$\frac{2}{0}$ \\
$\frac{1}{4}$ \\
\hline
\end{tabular}

is

a

岸

选

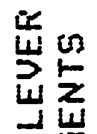

08

8 us

$\therefore$

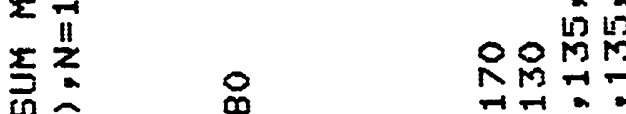

$+\underset{2}{2} \quad \stackrel{0}{2}$

$\rightarrow+2=0$

ㅇㅇㅇㅇㅡ.

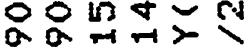

$\rightarrow+10$

○ิun

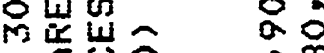

- 40요요

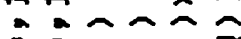

$00 \hat{0}=\hat{z} z$

$\cos z \geq z \Sigma$

$2 x+$

5 若

H L

$=21119$

OनलHनH+

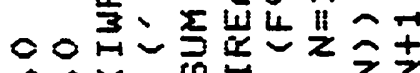

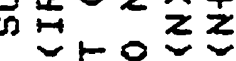

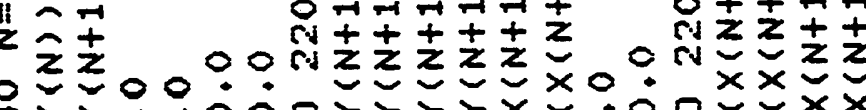

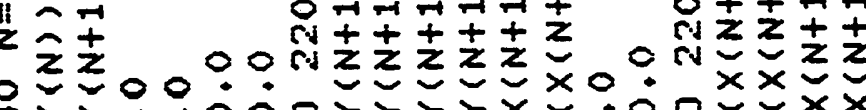

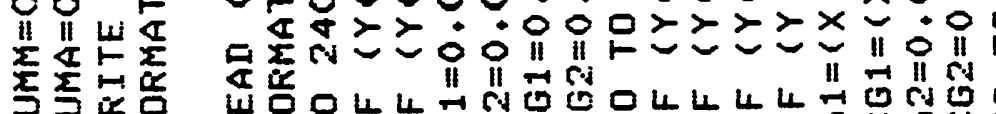

$$
^{-1} \& \text { o }
$$

음

응요욤

8

는

$\stackrel{\circ}{\circ}$

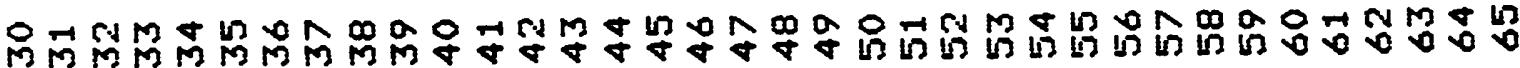




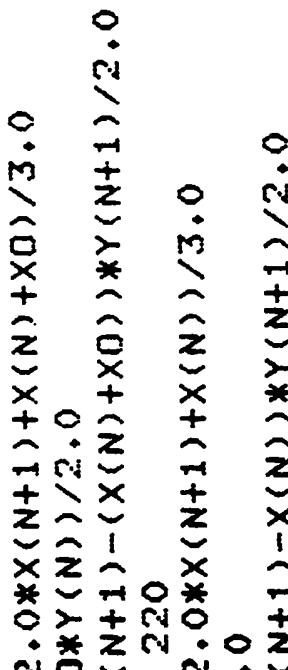


$\stackrel{8}{8}$

눙

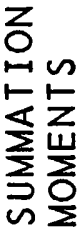

웅

안워

$<n$

トய

$\overleftarrow{0}$

0

:

上

금

n

$M$

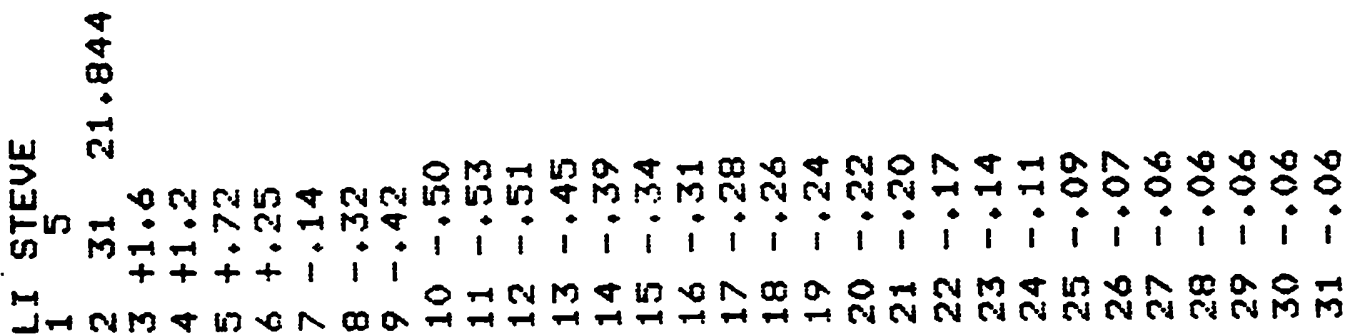




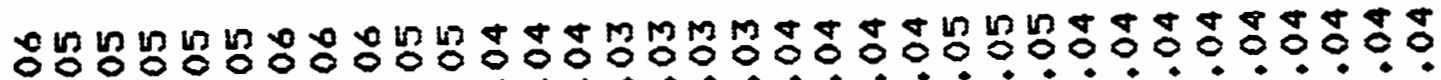

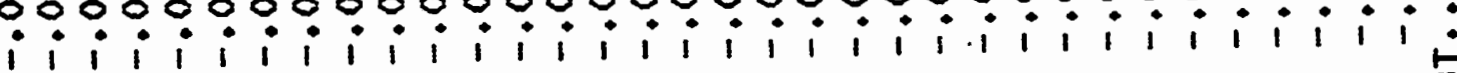

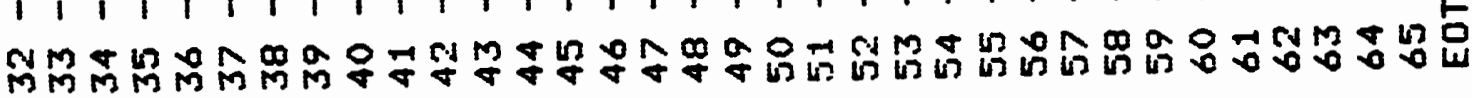




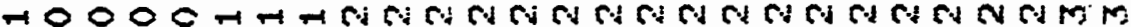
000000000000000000000000000

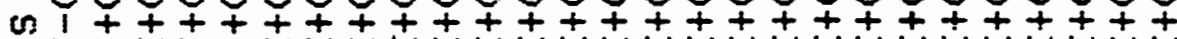

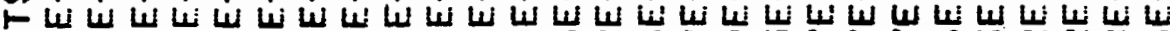

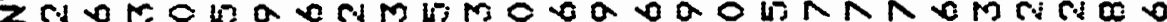
u 0 แ

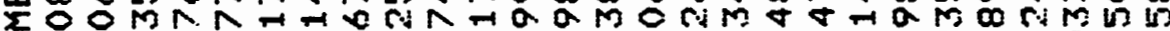

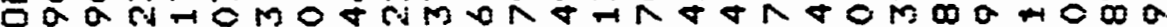

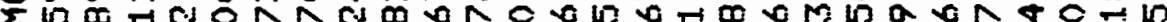

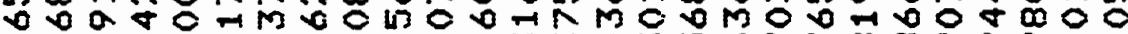

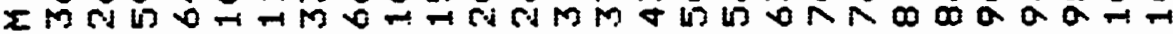

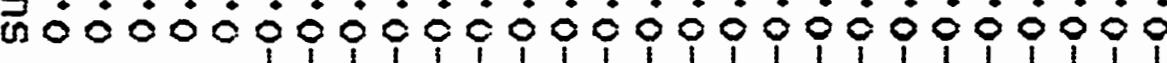

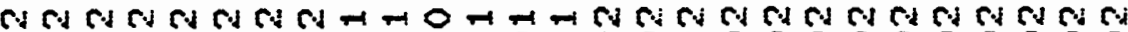
000000000000000000000000000

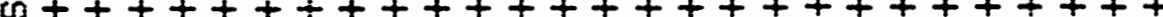
山ل U $\sigma$ r.

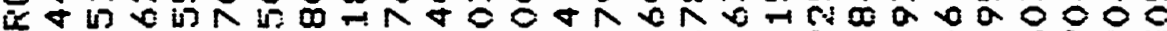

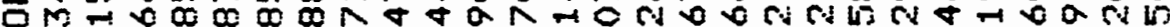

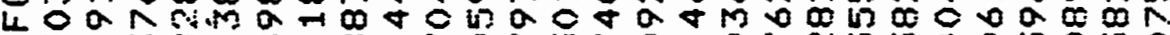

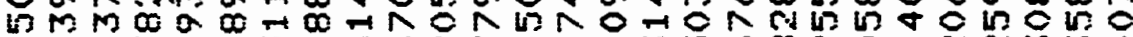

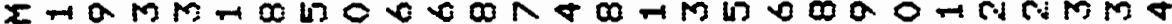

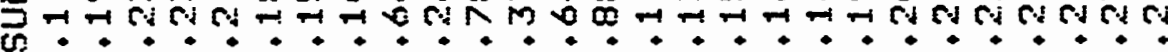
$\dot{0} \dot{0} \dot{0} \dot{0} \dot{0} \dot{0} \dot{0} \dot{0} \dot{0} \dot{0} \dot{0} \dot{0} \dot{0} \dot{0} \dot{0} \dot{0} \dot{0} \dot{0} \dot{0} \dot{0} \dot{0} \dot{0} \dot{0}$

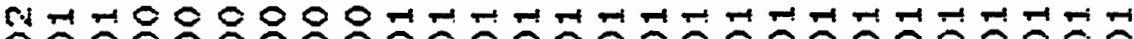

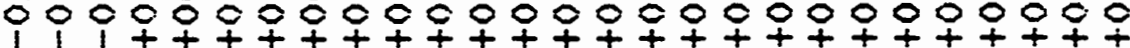
रा山س

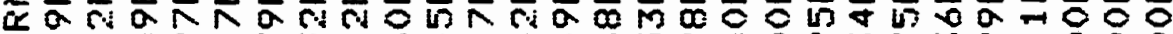

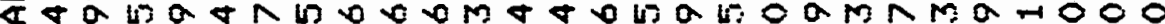

o O w r.

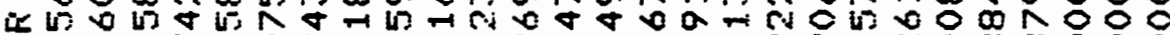

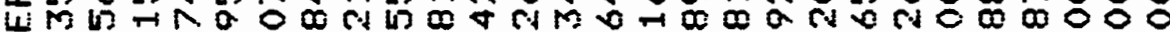
$\supset$ uा

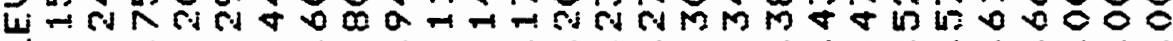
-i $\dot{0} \dot{0} \dot{0} \dot{0} \dot{0} \dot{0} \dot{0} \dot{0} \dot{0} \dot{0} \dot{0} \dot{0} \dot{0} \dot{0} \dot{0} \dot{0} \dot{0} \dot{0}$

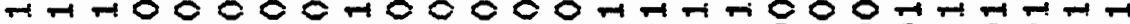
000000000000000000000000000

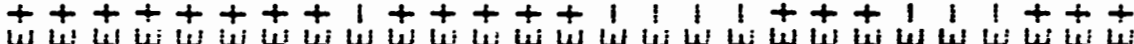

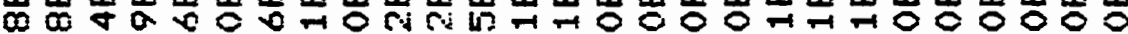

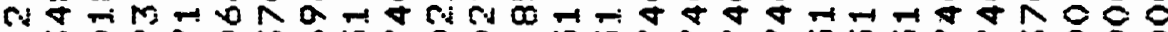

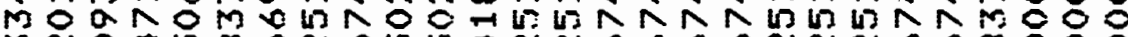

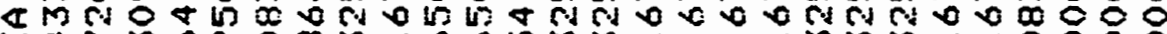

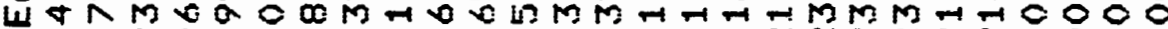

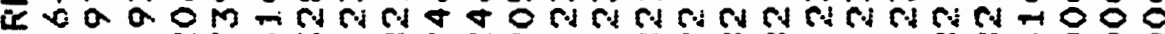
\&

- $\dot{0} \dot{0} \dot{0} \dot{0} \dot{0} \dot{0} \dot{0} \dot{0} \dot{0} \dot{0} \dot{0} \dot{0} \dot{0} \dot{0} \dot{0} \dot{0} \dot{0} \dot{0} \dot{0} \dot{0} \dot{0} \dot{0} \dot{0} \dot{0}$

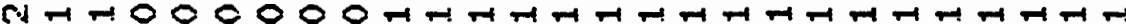

i

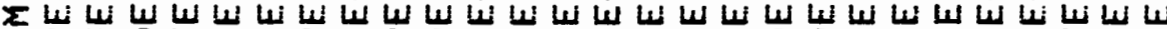
or

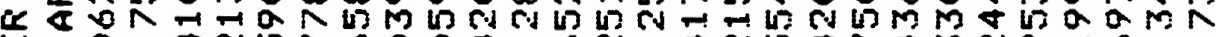

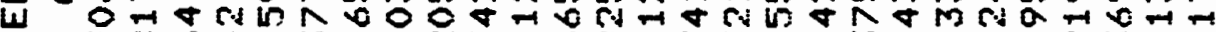
西 $\Sigma$ w wO $\supset \sigma \rightarrow 0 \% R-n$ o

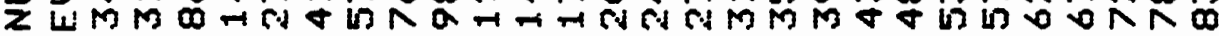
$\mu^{\prime} \dot{0} \dot{0} \dot{0} \dot{0} \dot{0} \dot{0} \dot{0} \dot{0} \dot{0} \dot{0} \dot{0} \dot{0} \dot{0} \dot{0} \dot{0} \dot{0} \dot{0} \dot{0} \dot{0} \dot{0} \dot{0} \dot{0} \dot{0}$

$\stackrel{2}{2}$

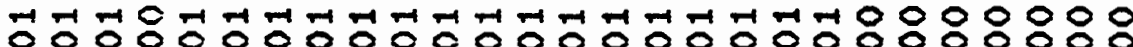

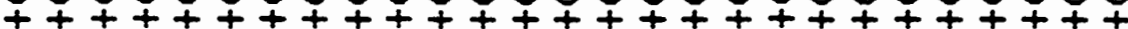

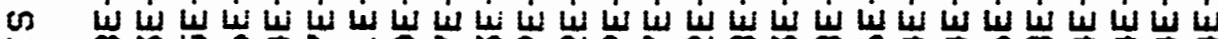

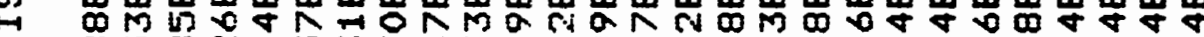
o 80 H

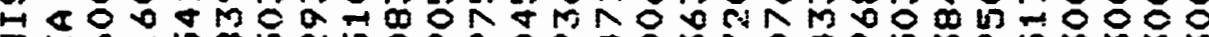

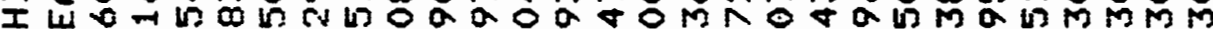

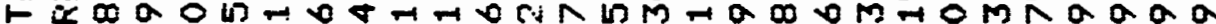
준 a a r.

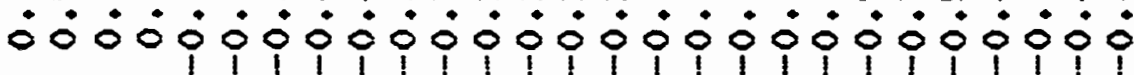


$M M M M M N M M M M M M M M M M M N M M M M M M M M M M M M M M M M M$ 00000000000000000000000000000000000 i

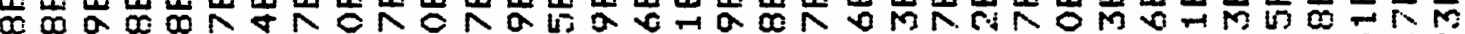

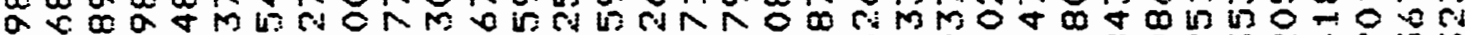

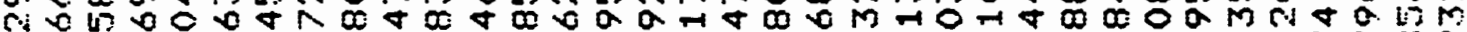

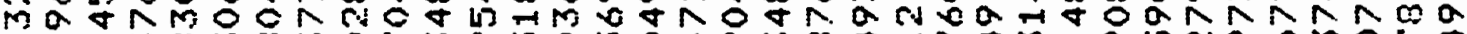

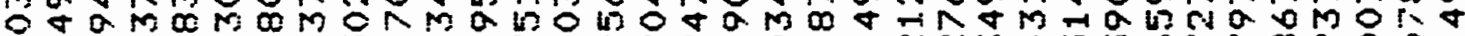

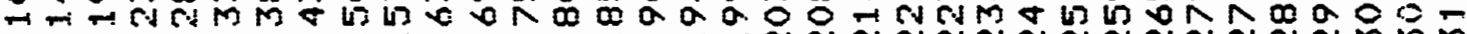

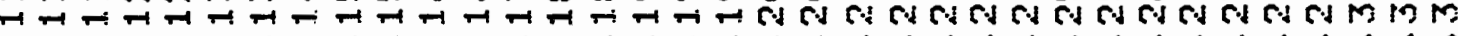
$\dot{0} \dot{0} \dot{0} \dot{0} \dot{0} \dot{0} \dot{0} \dot{0} \dot{0} \dot{0} \dot{0} \dot{0} \dot{0} \dot{0} \dot{0} \dot{0} \dot{0} \dot{0} \dot{0} \dot{0} \dot{0} \dot{0} \dot{0} \dot{0} \dot{0} \dot{0}$

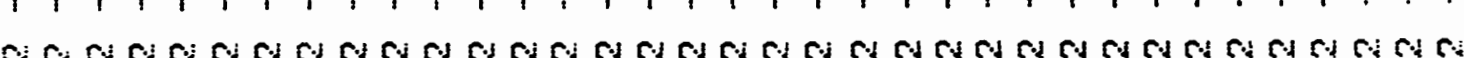

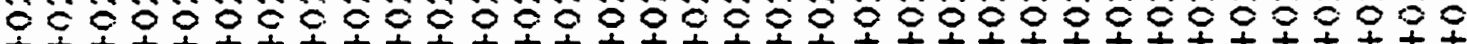
w

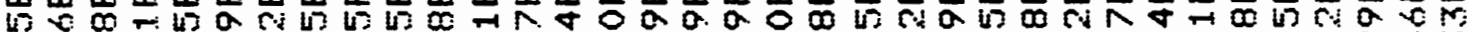

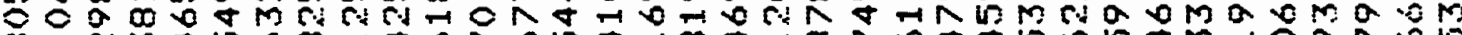

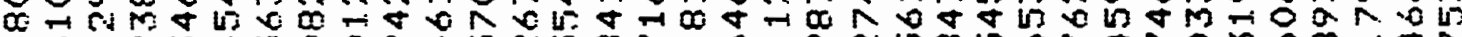
0 -

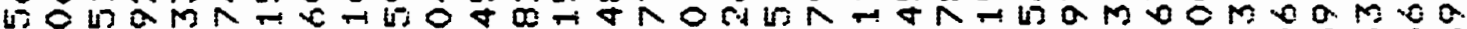

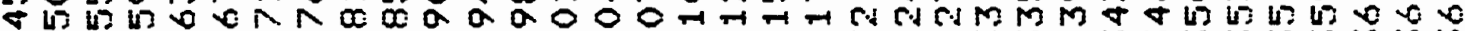

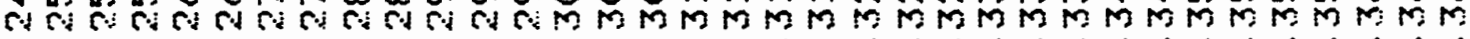
-

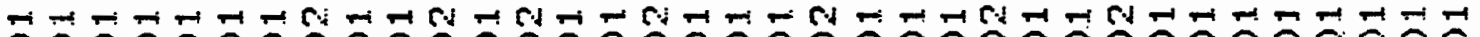

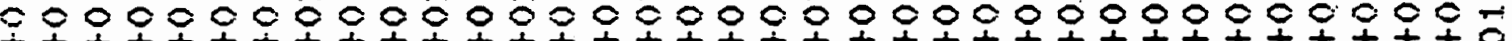

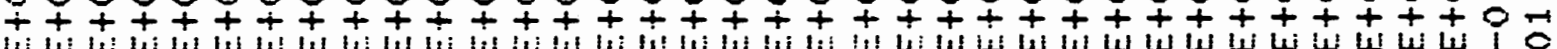

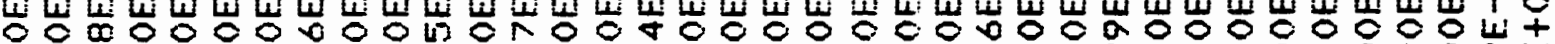

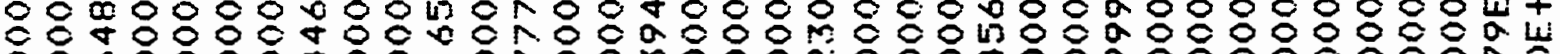

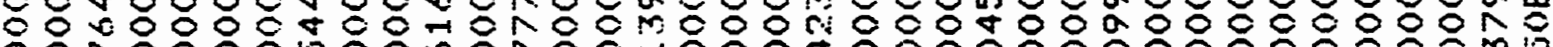

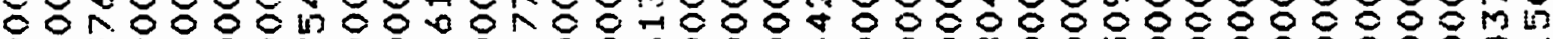

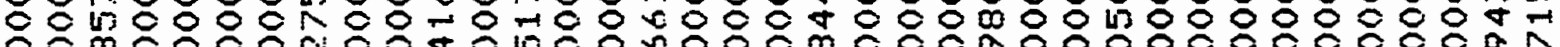

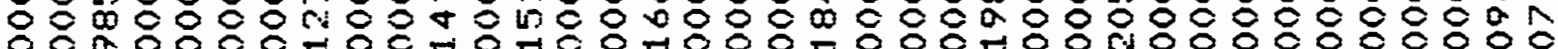

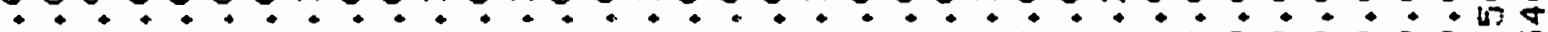

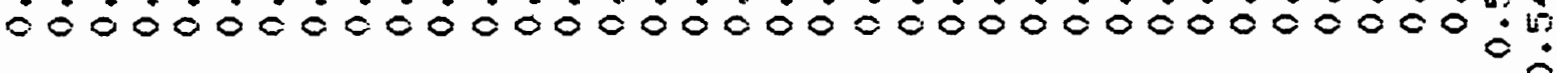

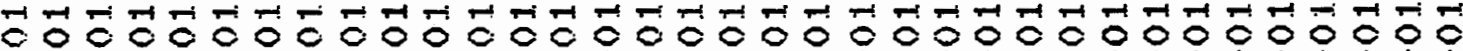
$++1++1+1+1+1+1+1+1+1+1+1+1+1+1+1+1+1+1+11$

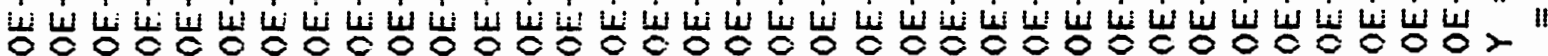

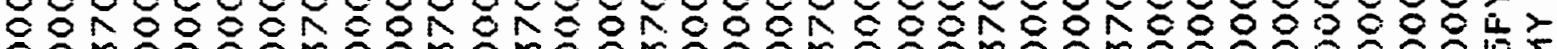

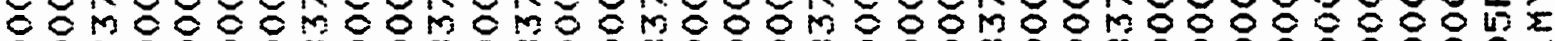

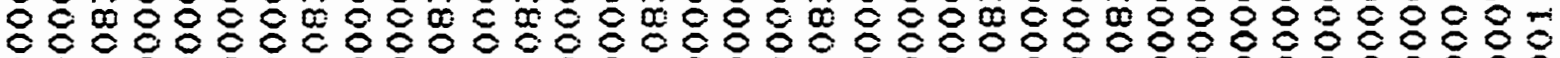

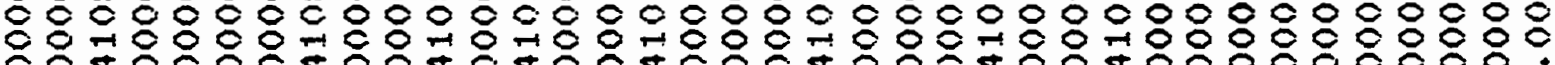
: - $\dot{0} \dot{0} \dot{0} \dot{0} \dot{0} \dot{0} \dot{0} \dot{0} \dot{0} \dot{0} \dot{0} \dot{0} \dot{0} \dot{0} \dot{0} \dot{0} \dot{0} \dot{0} \dot{0} \dot{0} \dot{0} \dot{0} \dot{0} \dot{0}$

HA 0000000000000000000000000000000000000

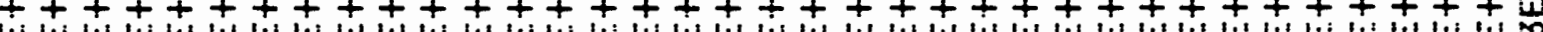

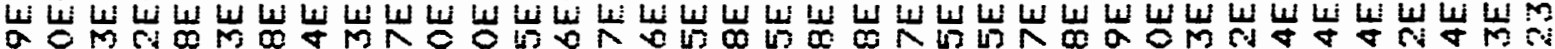

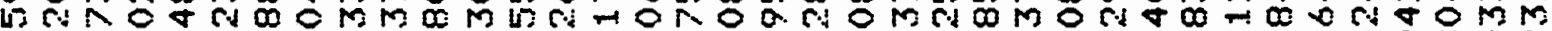

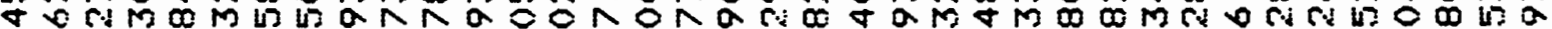

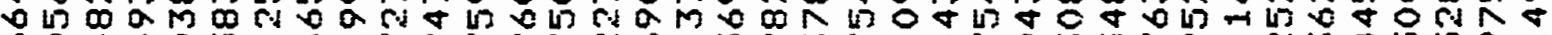
bo 0 - 0 r

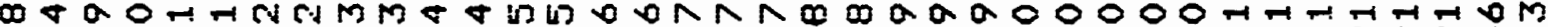

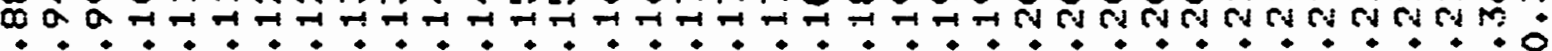
$\dot{0} \dot{0} \dot{0} \dot{0} \dot{0} \dot{0} \dot{0} \dot{0} \dot{0} \dot{0} \dot{0} \dot{0} \dot{0} \dot{0} \dot{0} \dot{0} \dot{0} \dot{0} \dot{0} \dot{0} \dot{0} \dot{0} \dot{0} \dot{0} \dot{0} \dot{0} \dot{0} \dot{0} \dot{0} \dot{0}$

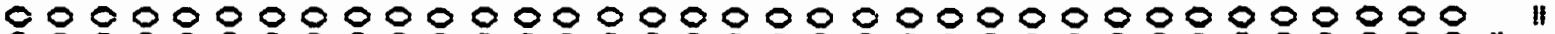

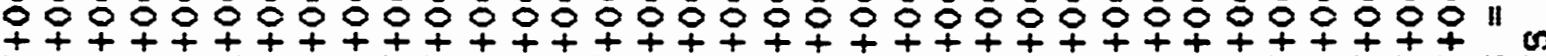
W山س

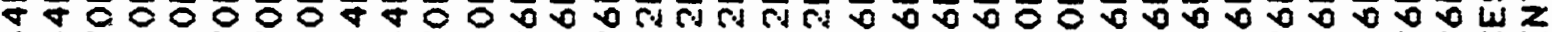

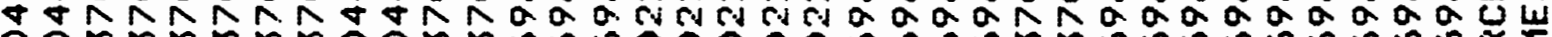

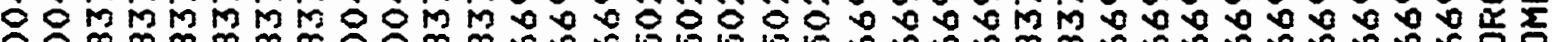
웅

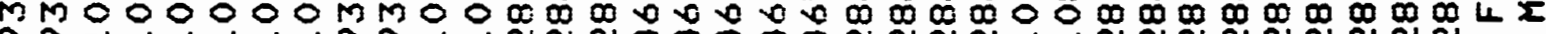

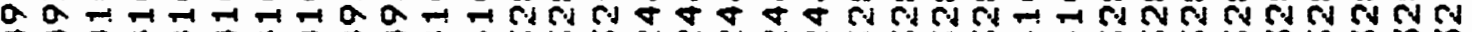

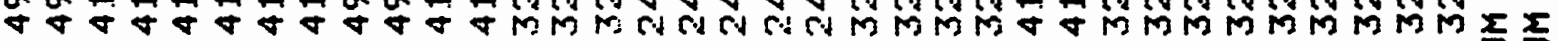

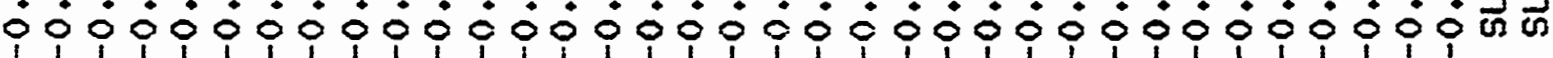

